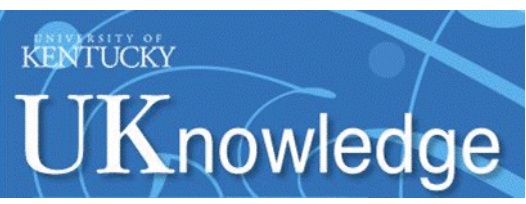

University of Kentucky

UKnowledge

\title{
Social Network Dynamics and Biographical Disruption: The Case of "First-Timers" with Mental Illness
}

\author{
Brea Perry \\ University of Kentucky \\ Bernice A. Pescosolido \\ Indiana University
}

Follow this and additional works at: https://uknowledge.uky.edu/sociology_facpub

Part of the Sociology Commons

Right click to open a feedback form in a new tab to let us know how this document benefits you.

\section{Repository Citation}

Perry, Brea and Pescosolido, Bernice A., "Social Network Dynamics and Biographical Disruption: The Case of "First-Timers" with Mental Illness" (2012). Sociology Faculty Publications. 20.

https://uknowledge.uky.edu/sociology_facpub/20

This Article is brought to you for free and open access by the Sociology at UKnowledge. It has been accepted for inclusion in Sociology Faculty Publications by an authorized administrator of UKnowledge. For more information, please contact UKnowledge@lsv.uky.edu. 
Social Network Dynamics and Biographical Disruption: The Case of "First-Timers" with Mental Illness

\author{
Digital Object Identifier (DOI) \\ https://doi.org/10.1086/666377 \\ Notes/Citation Information \\ Published in American Journal of Sociology, v. 118, no. 1. \\ (C) 2012 by The University of Chicago. All rights reserved.
}

The copyright holder has granted the permission for posting the article here. 


\title{
Social Network Dynamics and Biographical Disruption: The Case of "First-Timers" with Mental Illness ${ }^{1}$
}

\author{
Brea L. Perry \\ University of Kentucky \\ Bernice A. Pescosolido \\ Indiana University
}

This study examines how dynamics surrounding biographical disruptions compare to more routine fluctuations in personal social networks. Using data from the Indianapolis Network Mental Health Study, the authors track changes in patients' social networks over three years and compare them to a representative sample of persons with no self-reported mental illness. Overall, individuals at the onset of treatment report larger and more broadly functional social networks than individuals in the population at large. However, the number of network ties among the latter increases over time, whereas network size decreases slightly among people using mental health services. As individuals progress through treatment, less broadly supportive ties drop out of extended networks, but a core safety net remains relatively intact. The findings in this case provide evidence that social network dynamics reflect changing needs and resources: persons labeled with psychiatric disorders learn to manage illness, with functionality driving social interaction in times of biographical disruption.

Social networks, critical for individuals' life chances, are dynamic. Early on, Wellman and colleagues (1997) suggested that the dynamics of social

\footnotetext{
${ }^{1}$ We acknowledge financial support from the National Institute of Mental Health (grants K01MH00849, R29MH44780, and R24MH51669), the Indiana Consortium for Mental Health Services Research, and a National Science Foundation graduate
} 
networks are characterized by gradual changes common to the rhythm of daily life coupled with dramatic changes that occur on a more intermittent basis. Across a wide range of social phenomena, sociologists have examined how and why social networks evolve (e.g., Kossinets and Watts 2006; Feld, Suitor, and Hoegh 2007; Christakis and Fowler 2008). Yet, Lubbers and colleagues (Lubbers et al. 2010; Lubbers, Snijders, and Van Der Werf 2010) note that as social network analysis moved to a greater focus on dynamics, much of that effort has been on complete, whole, or sociocentric networks (e.g., Bearman and Moody 2004; Lazer et al. 2009). Here, we return to the question of how and when individuals' "small worlds" (Fischer 1982) change in the face of personal crises during those "bounded streams of social life" that represent "episodes" in the life course (Tilly 2001, p. 26; see also Pescosolido 1992).

Instability in personal social networks (i.e., egocentric ties to family, friends, or others in their communities) may follow naturally from marriage, birth of a child, and other significant events that mark expected role transitions and progression through the life course (Bost, Cox, and Payne 2002; Kalmijn 2003; Degenne and Lebeaux 2005; Gameiro et al. 2010). However, episodes that are unexpected may have a more sweeping impact on network dynamics. Research employing a variety of methods and examining experiences as diverse as job loss, divorce, foster care placement, and natural disaster suggests that personal crisis can lead to substantial changes in the structure and function of social networks (e.g., Jackson 1988; Rands 1988; Morgan and March 1992; Kaniasty and Norris 1993; Morgan, Neel, and Carder 1997; Terhell, Broese van Groenou, and van Tilburg 2004; Kalmijn and Broese van Groenou 2005; Perry 2006). Potential negative consequences include decreased contact, conflict and stress, and reduced intimacy and resource exchange (Erikson 1976; Terhell et al. 2004). Disruptive events may cause weaker ties to dissolve, compromising the structural integrity of the network and cutting off access to new information and opportunities (Burt 2002; Cornwell 2009). Conversely, disruptive events can present opportunities for the development of new relationships or can strengthen existing ties through the activation of formal and informal supporters (Kaniasty and Norris 1995; Tedeschi and Calhoun 1996; Gameiro et al. 2010). In short, the social circumstances

fellowship. We thank J. Scott Long, Eric R. Wright, Jane D. McLeod, Jack K. Martin, and Alex Capshew for comments. I would also like to acknowledge my father, Rus Perry (1944-2011), who quietly modeled selflessness and compassion for others and was always one of my core supporters. Direct correspondence to Brea L. Perry, Department of Sociology, 1515 Patterson Office Tower, University of Kentucky, Lexington, Kentucky 40506-0027. E-mail: breaperry@uky.edu 
of people's lives shape the structure, function, content, and membership of personal social networks at any particular point in time.

The onset of serious illness is one event that triggers a "network crisis" (Lipton et al. 1981). In his qualitative work on rheumatoid arthritis as biographical disruption, Bury (1982) describes serious illness as "the kind of experience where the structures of everyday life and the forms of knowledge which underpin them are disrupted" (p. 169). He argues that serious illness prompts mobilization of resources from social network members, "bringing individuals, their families, and wider social networks face to face with the character of their relationships in stark form, disrupting normal rules of reciprocity and mutual support" (p. 169). Moreover, entry into the health care system and the application of an illness label initiate changing roles and identities, evolving needs, and the formation of new formal relationships. These circumstances present a critical opportunity to explore how personal social networks respond to disruptive episodes and their fallout in the lives of individual members.

We begin with the network-episode model (NEM; Pescosolido 1991, 2006), drawn from the general social organization strategy (SOS) framework (Pescosolido 1992). For sociologists, illness has a long tradition of providing a window into basic social processes such as decision making, identity, and meaning making. From Hollingshead and Redlich's (1958) exploration of the link between social class and mental illness to Parsons's (1951) theoretical schema on the sick role, the case of illness is fundamentally intertwined with social networks, first in the community and then, with entry into treatment, in health care organizations. And, while the fortunes of the study of health and illness have been variable in sociology, this tradition's resonance in understanding multilevel social phenomena - the power of labels; the cultural, institutional, and interpersonal response to crises and daily problems; and issues of individual and structural discrimination-persists (Pescosolido 2006).

Identifying commonalities and differences in patterns of social network dynamics increases the stockpile of sociological knowledge on basic social processes and transitions in which, in many cases, as Lubbers, Snijders, and Van Der Werf (2010, p. 489) point out, "the knowledge base is not rich." Networks do not adhere to the principle of "one size fits all," and different problems, or stages of problems, call for different kinds of network resources. Existing research offers important clues about how individuals organize their social networks (into a strong group of core supporters and a weaker, more diverse set of peripheral ties) and why they do so (to facilitate access to a wide range of resources that can fulfill different needs as they arise; Wellman and Wortley 1990; Wellman and Gulia 1999; Hurlbert, Haines, and Beggs 2000; Wellman and Frank 2001; Perry and Pescosolido 2010). Understanding which life circumstances de- 
mand which kinds of networks reveals the motivations and mechanisms underlying even the most commonplace network dynamics, improving our knowledge of how and why changes in the lives of individuals have network-level consequences and ultimately shape life chances. Importantly, we know less about these changes in larger context, that is, how the social network dynamics of individuals experiencing biographical disruption compare to the ebb and flow of others around them who are not confronted by dramatic transitions.

In our longitudinal analysis, we focus on identifying critical stages and turning points in a group of individuals experiencing an episode of mental illness. ${ }^{2}$ Using data from the Indianapolis Network Mental Health Study (INMHS), we begin by examining network starting points among "firsttimers," individuals making their first major contact with the mental health treatment system and receiving a formal label of mental illness. Then, we document how the structure, function, and membership of personal social networks evolve over a three-year period among those coping with a disruptive illness episode, uniquely comparing these to dynamic patterns in a random sample of individuals in the surrounding general population.

We develop and empirically examine three sets of hypotheses: First, at the point of entry into the treatment career, how do respondents' social networks compare to those of individuals in the community without past or present mental health problems? Second, do these networks change over time to a greater or lesser degree than the networks of community members not experiencing such a disruptive event? Finally, how do networks evolve over time? By embedding social network dynamics in the context of the treatment career, we identify points at which changes in ties, support needs, and the types of people who fulfill them are likely to occur.

\section{THEORETICAL BACKGROUND: THE NETWORK-EPISODE MODEL}

Pescosolido's NEM $(1991,2006)$ was one of the first attempts to explicitly theorize the interplay between an episode of illness and evolving social

\footnotetext{
${ }^{2}$ The one-year incidence of "mental illness" $(26 \%)$ and "severe mental illness" $(6 \%)$ is similar to or exceeds the incidence of other critically disruptive social events studied under a social networks perspective (e.g., 9\% unemployed; 19\% divorced, separated, or widowed; U.S. Bureau of the Census 2002; Kessler et al. 2005; U.S. Bureau of Labor Statistics 2010). According to nationally representative studies, nearly $50 \%$ of Americans experience mental health problems at some point in their lives (Kessler et al. 2005), with some sociologists arguing that definitions of psychiatric disorder have broadened in the past few decades, encompassing a wider range of "normal" reactions to stressful experiences (Horwitz 2002) and becoming a normative feature of human experience in contemporary society.
} 
networks. Based on the SOS framework (Pescosolido 1992), the NEM was developed in response to static and individualistic decision-making models. It embeds health and health care pathways in the context of informal (i.e., personal or lay) and formal (i.e., professional) social networks. The first and most basic tenet of the SOS is that coping with disruptive episodes is a social process that involves contact with networks in the community, treatment system, and social services systems. Network ties are selectively activated to help handle problems that exceed one's personal capacity for coping (Bury 1982; Coleman 1982; Wellman 2000). Others may offer assistance that is unsolicited but dictated by norms of kinship or reciprocity (Wellman and Wortley 1990; Kaniasty and Norris 1993). Thus, in line with the NEM, individuals manage health problems through interactions with lay people and professionals who may recognize or dismiss symptoms and complaints; recommend or provide health services; and support, coerce, or nag about health behaviors, appointments, and medication compliance. Through these interactions, social networks influence key decisions about illness recognition and response, shaping illness behavior, health trajectories, and ultimately outcomes (e.g., Pescosolido, Brooks-Gardner, and Lubell 1998; Pescosolido et al. 1998; Gallant 2003; Cusack et al. 2004; Thoits 2011). These processes represent crucial and tailored coping mechanisms, particularly for individuals facing unfamiliar challenges, periods of elevated support needs, and fundamental disruptions of identity and activity (Lively and Smith 2010).

A second major tenet of the SOS is that disruptive episodes influence social network dynamics, shaping the structure, function, and content of personal and professional communities over time. In the case of illness, network characteristics such as the number and interconnectedness of regular discussion partners (i.e., structure); provision of advice, information, and instrumental or emotional support (i.e., function); and supporters' beliefs and attitudes toward health professionals (i.e., content) are in part dependent on conditions of illness (or another disruptive episode). For example, consistent with Parsons's (1951) classic sick role concept, the NEM posits that someone experiencing severe symptoms of mental illness may initiate requests for support and advice in order to cope with uncertainty and elevated needs or may receive guidance whether or not it is wanted. Likewise, ties between network members may develop as an ill person's family and friends coordinate and cooperate to meet his or her needs for emotional support or to help with chores, child care, or transportation (Pescosolido 1991). Empirical evidence suggests that social networks do respond in both positive and negative ways to a health crisis in the lives of individuals (Lipton et al. 1981; Blazer 1983; Breier and Strauss 1984; Grant and Wenger 1993; Wellman 2000; Karp 2001; Carpentier and Ducharme 2003; Perry 2011). 
Third, the SOS focuses on the career, arguing that disruptive episodes are characterized by interdependent patterns and pathways of decisions, social interactions, and experiences. The career concept has long been employed in the social sciences as a conceptual framework for explaining dynamic processes-for example, educational and cultural careers (Aschaffenburg and Maas 1997) and work careers (Elder and Pavalko 1993) - and has been applied convincingly to various aspects of illness (Goffman 1961; Suchman 1965). While initially defined as "a series of related stages or phases of a given sphere of activity that a group of people goes through . . . on the way to a more or less definite and recognizable end point or goal" (Roth 1963, p. 98), more recent theoretical and empirical work suggests a variety of pathways that individuals follow in response to illness (Pescosolido, Brooks-Gardner, and Lubell 1998; Pescosolido et al. 1998; Pavalko and Woodbury 2000; Carpentier and Ducharme 2003). Though progression is often nonlinear, stages of the illness career typically include illness onset, recognition of symptoms, entering treatment, complying with or rejecting treatment advice, and outcome (i.e., recovery, death, disability, or chronicity; Pescosolido 1991).

The treatment career is a subcomponent of the illness career for those individuals whose response pathways include professional caregivers (i.e., treatment providers). Entry into the medical, mental health, and sometimes criminal justice systems ushers in a completely new set of ties outside intimate networks. The role of these relative "outsiders"-doctors, social workers, and police, for example-may be both critical and short-lived, as dictated by institutional roles, requirements, and resources (Pescosolido, Brooks-Gardner, and Lubell 1998). However, for those who enter longterm care or remain in treatment, professional providers may become more prominent network members, supplementing or replacing family caregivers and more intimate ties (Carpentier, Lesage, and White 1999; Carpentier and Ducharme 2003).

Fourth, consistent with the career concept, the SOS asserts that different stages of disruptive episodes require unique types and amounts of support and elicit distinct patterns of network change. In other words, timing matters. Factors that are critical for initial response (e.g., relationship formation) are not likely the same as those important for continuity (e.g., relationship maintenance; Van Duijn, Van Busschbach, and Snijders 1999; Lubbers et al. 2010). Supporters tend to be most involved during the initial and most uncertain stages of an episode of severe illness, helping family or friends navigate the health and social services systems and adjust to new levels of ability and self-sufficiency (Carpentier et al. 1999). When individuals move successfully through the treatment career toward recovery or managed chronicity, informal support and involvement may wane as a sick person becomes increasingly independent or begins to rely 
more heavily on formal support (Karp 2001; Muhlbauer 2002; Carpentier and Ducharme 2003). Conversely, individuals experiencing a disruptive event may benefit from small networks of close ties in the initial period of intense fear or sadness but later gain more resources from a large network made up of weaker ties that provide access to new information, opportunities, and activities (Morgan et al. 1997). Because illness and other disruptive events are accompanied by a set of evolving challenges, support needs, and motivations that unfold over time, patterns of network dynamics may depend on a person's stage in the coping or adjustment process.

\section{HYPOTHESES ON STARTING POINTS AND DYNAMICS IN MENTAL ILLNESS}

Here, an episode of mental illness provides the substantive case to investigate the interplay between disruptive circumstances in individuals' lives and social tie dynamics through a network theoretical lens. The SOS sets the general frame for the development of NEM-specific hypotheses described below, which are tailored to mental illness. Using data from the INMHS, we examine network dynamics among individuals with mental illness who have recently entered the treatment career, having accessed the mental health system for the first time. Because personal social networks are characterized by gradual and random ebbs and flows in membership even during periods of relative stability (Wellman et al. 1997), dynamic patterns are compared to those for individuals with no reported history of mental illness, providing a unique comparison to a baseline level of variability. In addition, we examine changes in both the core network that taps strong ties and the broader network that includes weaker ties (Mok and Wellman 2007). Proposed hypotheses consider both where individuals' networks may be at the initial point of observable study and how they may evolve after the initiation of the treatment career (Lubbers, Snijders, and Van Der Werf 2010).

Starting points.-According to the NEM, understanding the social network dynamics of individuals with a serious illness requires a consideration of timing, including stage in the illness career. An advantage of the data employed in this analysis is the ability to examine a sample of individuals who are all entering the treatment career for the first time, reporting symptoms for no longer than two years. Existing research suggests that entry into treatment through voluntary means, coercion, or some combination of the two is typically the culmination of a period of acute crisis often involving serious problems such as danger of harm to self or others (Pescosolido, Brooks-Gardner, and Lubell 1998; Carpentier et al. 
1999; Muhlbauer 2002; Sharfstein 2009). The foundation of the NEM is the idea that managing the social, emotional, and economic crisis of acute mental illness requires contact with social networks in the community, treatment system, and social services system (Carpentier et al. 1999; Muhlbauer 2002). Family members tend to be key players in the first stages of the illness and treatment career, taking on a supportive role as ill people cope with the most threatening and immediate problems and learn to navigate the treatment system (Carpentier et al. 1999).

Because personal networks are one of the foremost ways that people cope with hardship and uncertainty, individuals in crisis may (1) try to shore up their networks to gain access to support or (2) find that others around them activate sectors of their networks that can provide resources (Pescosolido 1992; Hurlbert et al. 2000; Wellman 2000). In the early stages of the illness career, individuals may be particularly likely to succeed in efforts to actively procure or reactively be the beneficiary of support resources as members of the network respond to the onset of symptoms and elevated needs (see Perry 2011). Additionally, entry into treatment provides access to clinicians, staff, and fellow patients who may become friends or confidantes. Early empirical research on schizophrenia suggested that individuals experiencing their first episode have large networks, many strong ties, and high levels of contact with family and friends (Lipton et al. 1981; Breier and Strauss 1984). Thus, consistent with these findings and with the NEM more broadly, we propose the following illness-specific starting point.

Hypothesis 1.-The social networks of people with mental illness entering the treatment career are larger and provide more support functions compared to people without mental illness.

Network change.-While establishing starting points is critical, our chief concern is how social networks change over time in the face of biographical disruption. The NEM argues that progression through the illness career is accompanied by changes in the structure, function, and content of personal and professional communities (Pescosolido 1991). One measure of personal social network dynamics is the degree to which specific individuals move into and out of the network (i.e., membership turnover). Though research suggests that network membership in the general population is fairly unstable, with only about one-quarter to one-third of ties persisting over a decade (Suitor and Keeton 1997; Wellman et al. 1997), we expect higher rates of membership turnover among those facing a serious illness. Similarly, fluctuations in membership turnover will be reflected in changing network size and functionality over time as individuals experiencing disruption move through stages of the treatment career. Thus we present the following hypothesis.

Hypothesis 2.-As people with mental illness progress through the 
treatment career, their social networks exhibit higher levels of membership instability and larger changes in size and functionality compared to people without mental illness.

With respect to how networks change, dynamic social network patterns should mirror the progression of illness and treatment experiences typical of individuals just beginning the mental health treatment career. In other words, formulating hypotheses on network change requires a consideration of the unique evolution of needs, identities, and events that characterize the mental illness career, as well as the phases of caregivers' response to supporting individuals with mental illness (Karp 2001; Muhlbauer 2002; Carpentier and Ducharme 2003). While there may be a number of potential complexities and contingencies, we are interested here in broad patterns.

Consistent with the previous hypothesis on starting points, we might expect continuing network growth and increasing support as individuals with mental illness move through stages of the treatment career. Existing research suggests that network size increases and supporters remain heavily involved during the convalescent period following an acute episode of mental illness (Lipton et al. 1981; Blazer 1983; Breier and Strauss 1984; Litwak 1985; Carpentier and Ducharme 2003). As people adjust to the realities of living with mental illness and their new identity, family and friends may maintain a high level of involvement in the years following treatment to prevent relapse and maximize chances of recovery. They become more broadly supportive or even coercive, providing the kinds of assistance that they might not typically offer (e.g., financial support, help with daily living, etc.; Pescosolido, Brooks-Gardner, and Lubell 1998). Many individuals live with family members or in group homes as they transition from acute to long-term community-based care, which keeps them socially integrated and active (Lipton et al. 1981; Holschuh and Segal 2002). Further, being in community-based treatment, which often involves group therapy and access to clubhouses or other social opportunities, can lead to new relationships with others who share the consumer identity (Litwak 1985; Carpentier and Ducharme 2003). This suggests the following hypothesis.

Hypothesis 3a.-As people with mental illness progress through the treatment career, their social networks become larger and provide more support functions compared to people without mental illness.

Alternatively, if the above hypothesis on starting points is observed, the size and functionality of social networks might decrease over time. That is, with the emergence of symptoms and initial uncertainty of undiagnosed mental illness, peripheral supporters may become increasingly involved to bolster the existing social safety net (Karp 2001). Network size and functionality might peak near the point of entry into formal 
treatment and subsequently decrease as the need for informal support tapers off and symptoms are controlled. Existing research suggests that kin are very active in the early stages of the treatment career but become less involved as professionals take over some of their support functions (Carpentier et al. 1999; Muhlbauer 2002). Likewise, extended family members or friends may be temporarily activated when support needs are greatest but do not provide the long-term assistance that is typical of parents or adult children (Karp 2001). Research on individuals diagnosed with schizophrenia suggests that over time patients recovered their ability to cultivate new relationships and began to rely less heavily on family members and treatment providers (Breier and Strauss 1984). Decreasing network size and support functions may, in some cases, be an indication of progress toward independence, self-reliance, and recovery.

However, research on labeling and caregiver burden provides a less optimistic explanation for the same pattern. The stigma and loss of status associated with mental illness have been well documented, and formal labeling may lead to rejection by others or withdrawal from friends and family over time. Documented public stigma has important consequences for relationships and life chances (Link et al. 1989; Link and Phelan 1999; Martin, Pescosolido, and Tuch 2000). Further, networks may collapse as people in crisis become increasingly dependent on others and relationships become imbalanced (Grant and Wenger 1993; Williams 1995). That is, caring for someone with mental illness has been associated with substantial social, emotional, and economic burden (Loukissa 1995; Gallagher and Mechanic 1996; Perlick et al. 2005). Consequently, caregivers' patterns of involvement fluctuate according to their own emotional needs and sense of responsibility (Muhlbauer 2002; Carpentier and Ducharme 2003). In some situations, caregivers may experience extreme frustration, temporarily or permanently minimizing contact and involvement (Cuijpers and Stam 2000; Karp and Tanarugsachock 2000). This research suggests the alternative hypothesis.

Hypothesis $3 \mathrm{~b} .-$ As people with mental illness progress through the treatment career, their social networks become smaller and provide fewer support functions compared to people without mental illness.

Controls and nuances. - Two additional concerns are noted here, if even in a preliminary and exploratory manner. First, characteristics of the biographical disruption itself, in this case the nature of the mental health problems, may shape people's patterns of interaction or responses to the ill person. Consequently, we examine the effects of illness severity and diagnosis, which clinicians tend to regard as key indicators of social functioning (Pattison et al. 1975) and which the NEM sees as a fundamental foundation for illness and treatment career trajectories (Pescosolido 1991). There is a great deal of variation in the problems that fall under the 
umbrella of "mental illness." Some disorders (e.g., depression) are associated with social withdrawal, whereas others may cause increased sociability (e.g., bipolar disorder; Spitzer et al. 1990). Moreover, conditions such as schizophrenia and bipolar disorder, which often share psychotic features, provoke fear and harsh societal reactions (Phelan et al. 2000). Similarly, illness that is more severe is likely to be accompanied by visible signals that help is needed and to necessitate the mobilization of many network resources, producing a pronounced network response (Hurlbert et al. 2000; Wellman 2000; Perry 2011). In short, variations in symptoms and functioning undoubtedly shape the social network consequences associated with mental illness. In general, we expect that those with more severe, visible, and stigmatized mental illnesses experience higher levels of network change.

Second, because an individual's gender, race, age, and educational attainment may affect the structure and function of personal networks, as well as labeling processes (Marsden 1987; Ajrouch, Antonucci, and Janevic 2001; Peek and O'Neill 2001; Metzel 2003; Lubbers et al. 2010), these demographic characteristics are considered as controls. Sociodemographic status may shape network size and membership through differential access to potential network members (South and Deane 1993; Groot and Verberne 1997) or through differential response patterns in diagnoses and treatment relationships (Metzel 2003). These variations must be considered here because they can lead to different patterns of network dynamics through the treatment career.

\section{DATA AND METHODS}

\section{Sample}

Data come from the INMHS, a longitudinal study of the early treatment careers of people with mental illness. These data are unable to capture the full illness career since processes and events leading up to illness recognition or onset are not measured. However, because individuals were followed for up to three years, whether they remained in treatment or not, these longitudinal data do represent the start of the treatment career as well as a significant part of the illness career, albeit truncated on both ends.

Individuals making their first major mental health contact were recruited between 1990 and 1997. The largest public and private hospital (including an embedded community mental health center) in Indianapolis participated, with administrative staff notifying new clients about the study. Consenting individuals were administered the Structured Clinical Interview for DSM-III-R (Spitzer et al. 1990). Clients with a research 
diagnosis of major depression, bipolar disorder, or schizophrenia/schizoaffective disorder and an additional group with mild mental illness (adjustment disorder, dysthymia, etc.) were recruited into the study if they had a documented or self-reported mental illness history of no longer than two years. All new clients who met the sample criteria during a given time period were contacted, initially by hospital staff and then by research staff, for inclusion in the study (66.4\% agreed to be interviewed). ${ }^{3}$ Baseline in-depth interviews were conducted within the first three months of contact with the treatment facility, and two follow-up interviews occurred an average of 10 months and 24 months later. A total of 173 individuals participated and provided information about a total of 4,144 network ties over three waves. Two cases at the respondent level were dropped because of missing data on independent variables, resulting in an effective sample size of $171 .^{4}$ Respondents' networks were measured at up to three occasions, yielding 373 observations. While 140 of the 513 potential observations across three waves (27\%) are missing because of respondent attrition over time, the multilevel models employed and comparisons of respondents who did and did not drop out of the study reduce concerns about biases related to missing data (see below).

To compare social network starting points and change among people with mental health problems and those without them, parallel network data in the INGPS were collected from a sample of individuals in the general population in the same urban area and time period. As a random digit dialing 20-minute phone survey, typical epidemiological assessments of mental illness in use at the time of data collection (e.g., the composite international diagnostic interview; Kessler et al. 2005) were not feasible.

\footnotetext{
${ }^{3}$ Selection bias is a common problem in studies of people with mental illness, which tend to have small sample sizes and low response rates because of the difficulty of obtaining access to this population (e.g., Link et al. 1989). With a response rate of $66 \%$, selection bias may be affecting our results. Those with the most severe acute symptoms may have chosen not to participate or been unable to participate at baseline. If this is the case, the findings reported here regarding social network dynamics are conservative, since our findings suggest that illness severity is associated with greater levels of change over time. Census data indicate reasonable levels of similarity between the Indianapolis Network General Population Study (INGPS) sample and the city population, reducing concerns about selection bias in this sample.

${ }^{4}$ The sample sizes for both the mental illness and general population samples are modest, raising concerns about statistical power and the possibility of type 2 errors. To address this, post hoc power analyses were conducted (using the $\alpha$ level, number of predictors, observed $R$-squared, and number of observations) for every model. Overall, though the low power in a few models may have decreased sensitivity to small effects associated with demographic control variables, statistically significant effects of time in the treatment career and mental illness were detected. Thus, these power analyses increase confidence in the results pertaining to effects of mental illness over time- the central research question addressed here.
} 
However, individuals were excluded from participating if they reported any past or current mental illness or were determined to be confused, disoriented, intoxicated, and so forth by interview staff at the survey research center. There are two important differences between the INMHS and the INGPS. First, the latter interviews occurred via telephone rather than in person. Computer-assisted personal interview technology, random digit dialing, and a quota sample (with replacement) of at least 100 individuals were used. Second, data were collected approximately 10 and 21 months after the baseline interview (with the latest final interview occurring 24 months after baseline). Thus, regression estimates and statistics for the mental illness sample cover a longer period of time than the general population sample. To control for variation in length of time between actual interview dates, the measure of time used in all analyses is real number of years in the treatment career rather than interview wave (i.e., an artificial indicator of time). In total, data on 134 individuals in the INGPS were collected. One case was dropped because of missing data on independent variables, yielding a sample of 133 respondents and 335 observations across waves.

Sample profiles.-Baseline demographic characteristics indicate that over half the INMHS sample is female (64\%), and almost three-quarters is white (73\%; table 1). Respondents range in age from 16 to 72 , with a mean age of 30.6 years, and have completed 11.6 mean years of schooling (62\% with a high school diploma or equivalent; $13 \%$ with a four-year college degree). Over half the sample (52\%) was diagnosed with major depression, $24 \%$ with adjustment disorder, $13 \%$ with schizophrenia or a related disorder (e.g., schizo-affective disorder), $7 \%$ with bipolar disorder, and $4 \%$ with some other diagnosis.

Sociodemographic comparisons to U.S. census data suggest that the INGPS sample is reasonably representative of the general population of Indianapolis as a whole. The INGPS sample is about $53 \%$ women and $82 \%$ white. INGPS respondents are significantly older than the INMHS sample, with a mean age of 46.3 years $(t=7.06, P \leq .001)$. Moreover, respondents from the INGPS are significantly more educated, completing nearly two more years of schooling on average than their counterparts diagnosed with mental illness (13.5 years; $t=9.36, P \leq .001){ }^{5}$

\footnotetext{
${ }^{5}$ To determine the extent to which the INGPS sample is representative of the general population, one-sample binomial and $t$-tests were conducted comparing statistics from this sample to those from U.S. census data. These indicate no significant gender, racial/ ethnic, or age differences between the sample without mental illness and the general population. Results pertaining to education level are mixed. Specifically, there is no significant difference in the proportion with a college degree, but a significantly larger proportion of the INGPS sample had earned a high school diploma compared to census data for the nation as a whole $(P<.05)$. However, the sample without mental illness
} 
TABLE 1

Sample Descriptive Statistics, INMHS $(N=171)$ ANd INGPS

$(N=133)$

\begin{tabular}{lccc}
\hline \hline & $\begin{array}{c}\text { Mental } \\
\text { Illness }\end{array}$ & $\begin{array}{c}\text { General } \\
\text { Population }\end{array}$ & $\chi^{2} / F$ \\
\hline Female $(\%) \ldots \ldots \ldots \ldots \ldots \ldots$ & 63.7 & 53.4 & 3.3 \\
White $(\%) \ldots \ldots \ldots \ldots \ldots \ldots$ & 73.1 & 82.0 & 3.2 \\
Age (years) $\ldots \ldots \ldots \ldots \ldots \ldots$ & 30.6 & 46.3 & $87.6^{* * *}$ \\
Education (years) $\ldots \ldots \ldots \ldots$ & 11.6 & 13.5 & $48.7^{* * *}$ \\
Diagnosis: & & & $\ldots$ \\
Major depression $(\%) \ldots$ & 52.0 & $\ldots$ & $\ldots$ \\
Bipolar $(\%) \ldots \ldots \ldots \ldots \ldots$ & 7.0 & $\ldots$ & $\ldots$ \\
Schizophrenia (\%) $\ldots \ldots \ldots$ & 12.9 & $\ldots$ & $\ldots$ \\
Mild disorder $(\%) \ldots \ldots \ldots$ & 28.1 & & $\ldots$ \\
\hline
\end{tabular}

$* P<.05$ (two-tailed test).

$* * P<.01$.

$* * * P<.001$.

The significant differences in age and educational attainment between the INGPS and INMHS samples likely reflect the well-known etiology associated with mental illness. Over four-fifths of INMHS respondents have been diagnosed with a mood disorder and have experienced onset within the past two years (according to selection criteria). The median age of onset for mood disorders is 30 years, and the median age in the INMHS sample is 29 (Kessler et al. 2005). Indeed, age differences between the INMHS and INGPS samples increase confidence that this study captures people relatively early in the mental illness career and at the start of the treatment career. Likewise, significant differences in mean years of schooling reflect the impact of mental illness on educational attainment (McLeod and Kaiser 2004). Individuals with mental illness are about one and a half times as likely as those without one to drop out of high school before earning a diploma and nearly three times as likely to fail to complete a four-year degree once they have entered college (Kessler et al. 1995). Though the sociodemographics of the INMHS sample are likely representative of the population of individuals with mental illness (and particularly mood disorders) as a whole, these patterns do make it difficult to disentangle the effects of mental illness from the influence of youth and low socioeconomic status. For this reason, sociodemographics are used as control variables in all models.

is not significantly different when compared to the state of Indiana. This reduces concerns about the representativeness of our "general population" sample. 
Measures

Name generators. - These analyses focus on dynamic properties of individuals' personal networks. Egocentric, or individual-centered, social network research employs name generators to elicit lists of associates with particular functions (e.g., discussion partners) or statuses (e.g., close kin). Here, name generators are used to examine change over time in two types of networks. First, we employ a problem-focused variant of the "important matters" question from the General Social Survey (GSS; Marsden 1987). This name generator asks individuals to list people they talk to about health issues and who approach them to talk about these matters "whether you want them to or not." Findings from previous research using these data (Perry and Pescosolido 2010) indicate that health and important matters networks do overlap but that characteristics of the former are a stronger predictor of critical health and treatment-related outcomes. ${ }^{6}$ The health-focused network is also a better theoretical fit for this analysis since we are concerned with network changes that occur as a result of a specific problem (i.e., a disruptive health episode). Throughout this study, we call this the "core health network" since previous research demonstrates that it is composed largely of close friends and family members who provide many support functions and have frequent contact with the ill individual (Perry and Pescosolido 2010).

Second, in addition to the core health network, the INMHS includes data on respondents' ties across a broad range of domains: household, family, romantic partnerships, work and school ties, friends, acquaintances, people with common problems, and treatment providers. Each domain has a corresponding name generator, with no limitations on the number or types of people respondents could name. This extended network (Hammer 1983) is used to examine the nuances discussed earlier: is there a difference between what happens to networks of closer discussion partners versus the larger, more heterogeneous group of ties? Changes in this extended network may also be more likely to reflect labeling and other negative processes (Perry 2011). The number and variety of different name generators suggest that this approach provides a near inventory of people who have regular contact with respondents (hence our term "total network"), including people of great significance (e.g., core supporters) as

\footnotetext{
${ }^{6}$ Initially, an examination of changes in general important matters networks (replicating the GSS question exactly) of the INMHS and INGPS samples across time was included in this analysis, providing a third set of results. However, these were later omitted. Most important, dynamic patterns in the important matters network mirror those in the core health network across all measures, providing no new insight into the network processes of interest. These results on the important matters networks are available on request.
} 
well as those who may play a more peripheral or unidimensional role (e.g., treatment providers, neighbors, etc.).

Dependent variables. - To document social network dynamics, changes in three critical, but distinct, properties of personal networks are traced over time. Structure is measured by network size. Function is measured by the number of different support activities and resources provided by the core health and total networks. Finally, membership turnover describes the amount of change in the actual individuals making up each of the networks. These characteristics are computed separately for the core health and total networks. Previous studies suggest that the name generators and measures of personal social networks used in these analyses are reasonably reliable and valid (Wright and Pescosolido 2002; Perry and Pescosolido 2010; Perry 2011).

Network size at each wave is measured by the number of ties mentioned in response to the health matters name generators. For the total network, this is the sum of unique ties mentioned throughout the interview (i.e., no ties are double counted). There are no missing data on these variables that are not attributable to patterns of participation across waves. That is, after each name generator, respondents were asked why individuals mentioned in previous waves were not mentioned currently. Data were corrected or reasons for noninclusion in the current wave were recorded. Analyses of even the uncorrected data indicated low measurement error (Wright and Pescosolido 2002).

The total number of support functions provided by each associate is the sum of five dummy variables, including discussion partner ("listening to you"), emotional support ("telling you they care"), information and advice ("making practical suggestions"), instrumental support ("helping with things like chores or transportation"), and financial support ("giving/ loaning you money"). These are coded 1 if the associate provides the support function and 0 otherwise. The number of support functions provided by each associate is averaged to give a mean for the network ranging from 1 to 5 . If respondents said that they did not discuss health or important matters with anyone, the functionality variable contains a missing value ( $1 \%$ of observations). Further, about $14 \%$ of observations are missing because of nonresponse and random interviewer error (i.e., the respondent was never asked about support functions or data were not recorded).

Finally, turnover in network membership is calculated using two waves of data. This variable represents the percentage of network members who are dropped or added between one wave and the next. The total number of unique network members across two consecutive waves is determined. The number of associates who appear in only one of the two waves (i.e., 


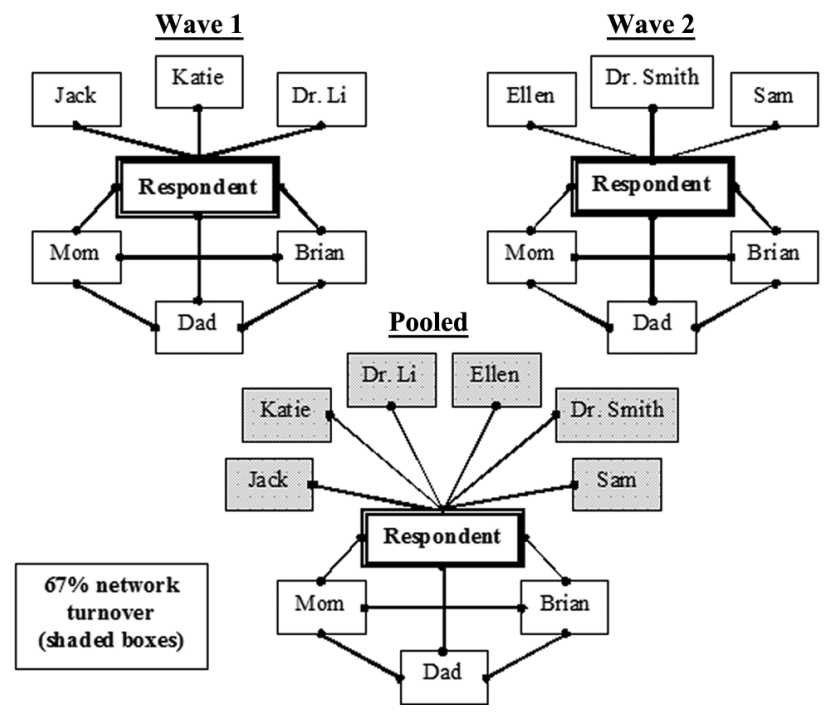

FIG. 1.-Hypothetical illustration of a typical egocentric subnetwork of important matters discussants and the measurement of membership turnover.

ties dropped/added) is calculated. The second number is divided by the first, giving the percentage of unstable ties across waves.

Figure 1 illustrates the concept and measurement of membership turnover employed here. In this hypothetical situation, a respondent has six ties at both waves 1 and 2, though the associates who make up the network change across waves. The percentage of turnover is equal to the number of ties dropped or added $(3+3)$ divided by the number of unique ties across waves 1 and $2(6+3)$, which is about $67 \%$. Importantly, the size of this network is the same across waves, but a substantial amount of membership turnover underlies an apparent stability in size.

Because the turnover measure is calculated using two consecutive waves of data, the maximum number of observations on percentage of turnover is two (i.e., wave $1 \rightarrow 2$ and wave $2 \rightarrow 3$ ). Further, if a respondent participated in only one wave of the study, the turnover variable has a missing value. In effect, the analysis of turnover is based on a subset of respondents who were present in two or more waves $(N=223$, or $73 \%$ of the original analysis sample). Comparisons of this subsample to respondents who were present in only one wave suggest that the two groups are similar on sociodemographic characteristics as well as psychiatric diagnosis and symptom severity. The only exception is education level, with respondents who dropped out of the study reporting about one less year of schooling, on average, than those who did not $(t=3.77, P \leq .001)$. 
Thus, findings pertaining to network turnover may not be applicable to individuals with very low levels of education (i.e., less than high school).

Independent variables. - A variable equal to the number of years since the baseline interview is included to assess the effects of time in the treatment career. This is equal to $.08(1 / 12)$ at baseline for all respondents because most interviews occurred within one month of entering treatment. To identify nonlinear relationships, time squared was also calculated but was later dropped because of nonsignificance.

As described earlier, sociodemographic controls are included as a series of independent variables. These include gender $(1=$ female, $0=$ male $)$, race $(1=$ white, $0=$ black), age at baseline (in years), and education (years of schooling). To explore the effects of different degrees of support needs and stigma, as well as capture distinct constellations of symptoms, mental illness is measured using two constructs: illness severity and diagnosis. ${ }^{7}$ Dummy variables for no mental illness (i.e., general population respondents), mild disorder (i.e., adjustment disorder and dysthymia), major depression, bipolar disorder, and schizophrenia are included in the models.

\section{Analytic Strategy}

Analyses explore the effects of time on the structure, functionality, and membership turnover of social networks. Two-level variance components models that account for within-subject heterogeneity (intraclass correlations on these dependent variables range from .13 to .56) are employed using Stata's (2011) xtreg command with the maximum likelihood random-effects (mle) specification. ${ }^{8}$ These models reflect time points (level 1) nested in respondents (level 2) and contain respondent-level (i.e., clusterspecific) random intercepts (Rabe-Hesketh and Skrondal 2008). These

\footnotetext{
${ }^{7}$ Ideally, measures of both severity and diagnosis would be included in the models, but substantial collinearity between the two prohibits this. Diagnoses included in the "mild" category typically have less severe consequences for well-being and life chances. They are also "reactive" disorders, meaning that they involve extreme responses to negative life events and conditions that are distressing to most anyone who experiences them (e.g., divorce, death of a loved one, job loss, etc.). As the middle ground between mental illness and "mental health," this category provides an apt comparison group in analyses of the total network in which no data on the general population are available.

${ }^{8}$ Random-effects regression models using the generalized least squares (GLS) estimator (re option) rather than the maximum likelihood estimator (mle option) were also computed. However, results did not differ in any meaningful way. Because weighted regression is not permitted when using the GLS estimator in Stata and weighting commands are used to obtain variance-unconstrained standard errors for mental illness group coefficients, the maximum likelihood estimator was chosen for the final set of models. Full results are available on request.
} 
models are a good fit for these data because of the number of missing observations across waves and the variation in length of time between interviews. The unbalanced nature of our data renders many other longitudinal models inappropriate, including cluster robust standard errors (Collins and Sayer 2001).

For example, the two-level model with two covariates for network size $y_{j k}$ in time point $i$ for respondent $j$ can be written as

$$
y_{j k}=\beta_{1}+\beta_{2} x_{2 i j}+\beta_{3} x_{3 i j}+\zeta_{j}+\varepsilon_{i j} \text {. }
$$

In this model, $i$ corresponds to time point (i.e., level 1 ) identifier, $j$ to respondent (i.e., level 2) identifier, $\zeta_{j}$ to the random intercepts, and $\varepsilon_{i j}$ to the level 1 residual. Together, $\zeta_{j}$ and $\varepsilon_{i j}$ represent the random part of the model, and the other components are the fixed part of the model. Further, the random-effects model assumes that (1) the random intercepts are independent across respondents, (2) the random intercepts are independent of the level 1 residuals, and (3) level 1 residuals are independent across units (Rabe-Hesketh and Skrondal 2008).

To assess whether the effect of time on social networks varies for people in different mental illness groups, we run a series of models using a pooled sample. These add an interaction term for time in the treatment career (in years) multiplied by a set of dummy variables measuring mental illness to a base model. Where time represents years in the treatment career, dep is a dummy indicating depression, bip is a dummy indicating bipolar disorder, sch is a dummy indicating schizophrenia, and mild is a dummy indicating less severe disorders (omitted variable is no reported mental illness), this model can be written as

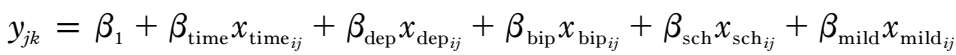

$$
\begin{aligned}
& +\beta_{\text {time } \times \text { dep }}\left(x_{\text {time } i j_{i j}} \times x_{\text {dep } i j_{i j}}\right)+\beta_{\text {time } \times \text { bip }}\left(x_{\text {time }_{i j}} \times x_{\text {bip } i j_{j}}\right) \\
& +\beta_{\text {time } \times \text { sch }}\left(x_{\text {time }_{i j}} \times x_{\text {sch }_{i j}}\right)+\beta_{\text {time } \times \text { mild }}\left(x_{\text {time }_{i j}} \times x_{\text {mild }_{i j}}\right)+\zeta_{j}+\varepsilon_{i j} .
\end{aligned}
$$

For the above-specified model, the effect of time for the omitted group (i.e., individuals with no reported mental illness) is simply $\beta_{\text {time }}$ and the effect for any included group is $\beta_{\text {time }}+$ the interaction term for that diagnosis (e.g., $\beta_{\text {time }}+\beta_{\text {timexdep }}$ for those with depression). Raw $\beta$ 's are reported in tables whereas group-specific effects are presented in the text and in figures to facilitate interpretation.

Because of the large number of group differences being examined here and the potential this introduces for biased standard errors, we assess significance tests for interaction terms by estimating the regression equations without constraining the residual variances of the mental illness groups to the same value (Gould 2005). Using weighted regression, we allow residual variances to vary across groups, resulting in standard errors 
identical to those produced when models are estimated separately by group. To aid interpretation, plots of predicted values from interaction models are presented with control variables set equal to their means. Significance tests from the variance-unconstrained models are presented below each figure.

Because data on network size are skewed heavily to the right, ${ }^{9}$ a $\log$ transformation is used to correct the distribution (Manning and Mullahy 2001). For ease of interpretation, predicted values for network size are retransformed into the original scale. To correct for biased estimation of the arithmetic mean, a smear factor based on the distribution of residuals is calculated and added to the predicted logged value before calculating the exponential (Manning and Mullahy 2001; Afifi et al. 2006).

Finally, analyses comparing characteristics of associates who remain in the network and those who exit are conducted to provide insight into mechanisms of network dynamics. For example, changes in the mean level of supportiveness of the networks may be attributable to patterns of network growth or attrition rather than to each individual member of the network providing more or less support. For example, if a disproportionate number of less broadly functional ties exited the network, this would increase the mean number of support functions provided by those in the reconfigured network, even if supportiveness remained stable for each individual. Likewise, comparing characteristics of individuals entering and exiting the networks can help determine whether the mechanisms driving network dynamics are stigma, caregiver burden, or support processes.

\section{RESULTS}

Starting Points for First-Timers and the General Population Compared

Social network characteristics of the first-timers diagnosed with mental illness and of the individuals in the general population sample reveal some important differences in initial core health networks (table 2). While the level of membership turnover in the core health network does not differ significantly across groups, people with mental illness discuss healthrelated matters with more associates than do people in the general population (bipolar $=4.9$, major depression $=4.0$, mild disorder $=3.5$,

\footnotetext{
${ }^{9}$ The results for log of network size have been checked for robustness. Substantively, results do not change across models when either a Poisson or a negative binomial regression for count outcomes is employed, though in one instance the negative binomial model does not converge. The models presenting linear regression combined with the log transformation are retained in the article because these permit a direct comparison with variance-unconstrained models. Full results are available on request.
} 


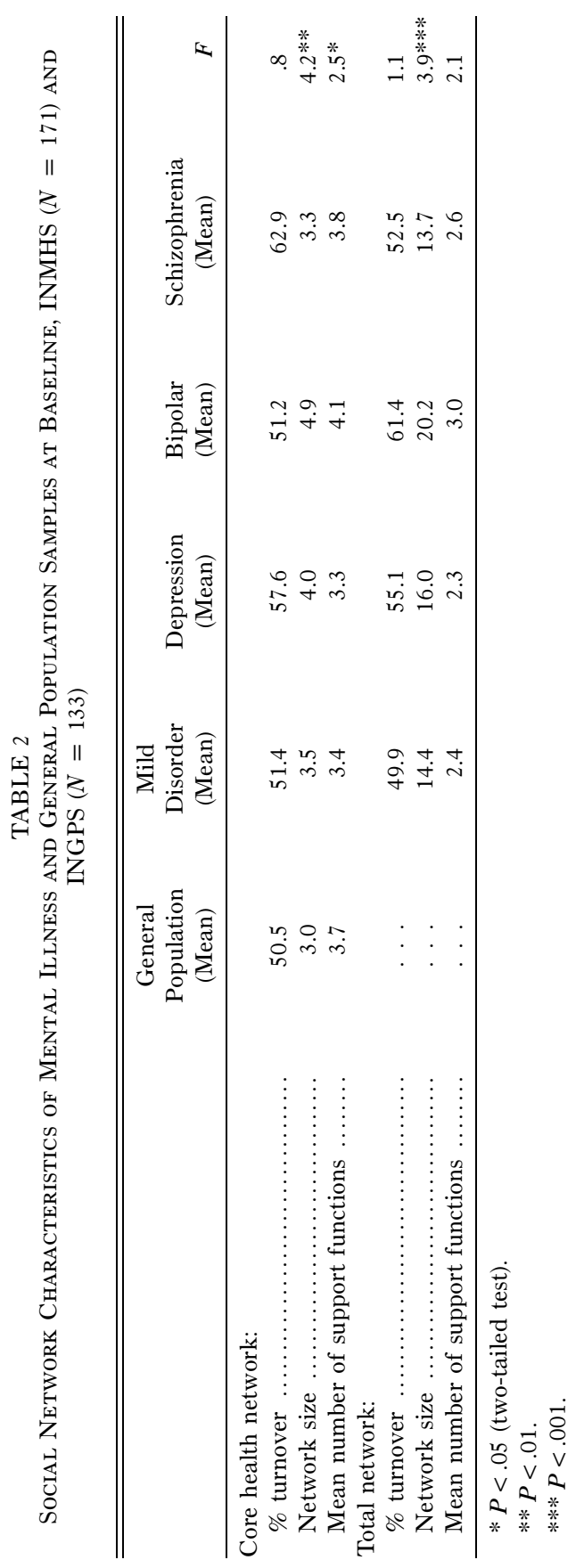


schizophrenia $=3.3$, no mental illness $=3.0 ; F=4.2, P \leq .01$ ). There are also significant differences in the number of support functions provided by the core health network, but these results are mixed and less pronounced. People with bipolar and schizophrenia receive more support functions than those in the general population (4.1 and 3.8 vs. 3.7, respectively), and those with depression and mild disorders receive less (3.4 and $3.3 ; F=2.5, P \leq .05$ ).

Results for initial differences in the total network also reveal no significant differences in the percentage of turnover across groups. However, people with mental illness, particularly those with bipolar disorder, have larger networks than those without. Individuals diagnosed with bipolar disorder report 20.2 network members compared to 16.0 among those labeled with depression, 14.4 among those with a mild disorder, and 13.7 among those with schizophrenia. There are no significant differences in the number of support functions in the total network across diagnoses.

In all, the descriptive findings are largely consistent with our hypothesis on starting points (hypothesis 1), which posits that individuals coping with biographical disruption due to mental health problems will have networks that are larger and more broadly functional than those without mental illness. Support for this hypothesis is strongest for the core health network and people diagnosed with bipolar disorder.

Patterns of Change for First-Timers and the General Population Compared

Core health networks. - Regression results and plots of predicted values (table 3; figs. 2-4) provide information about how core health networks change over the treatment career and whether patterns of change differ for people with and without labeled mental illness. Figures are created using regressions that include a set of interaction terms for time and mental illness status. Changes in the level of membership turnover in the core health network are reported in table 3 . There is no significant effect of time in the baseline model (see model 1), but there is evidence of group differences in the influence of time on membership turnover. According to model 2 and figure 2, the percentage of membership turnover decreases for those without a mental illness $(b=-0.09, P \leq .05)$ and for those with schizophrenia $(b=-0.10)$ and remains fairly stable for those labeled with a mild disorder $(b=0.01)$. There are no statistically significant differences between these three groups. In contrast, for individuals with major depression, the predicted percentage of membership turnover increases from about $55 \%$ to $75 \%$ over two and a half years $(b=0.08, P \leq .001)$. For those labeled with bipolar disorder, it nearly doubles, increasing from $48 \%$ to $85 \%(b=0.16, P \leq .01)$. 
TABLE 3

Random-Effects Linear Regression of Sociodemographics, Mental Illness Status, and Time on Characteristics of the Core Health Network, INMHS SND INGPS

\begin{tabular}{|c|c|c|c|c|c|c|}
\hline & \multicolumn{2}{|c|}{$\begin{array}{l}\% \text { MembershiP } \\
\text { TuRnOVER }\end{array}$} & \multicolumn{2}{|c|}{$\begin{array}{c}\text { LoG OF Network } \\
\text { SIZE }\end{array}$} & \multicolumn{2}{|c|}{$\begin{array}{l}\text { Mean Number of } \\
\text { Support Functions }\end{array}$} \\
\hline & 1 & 2 & 3 & 4 & 5 & 6 \\
\hline Female...$\ldots \ldots \ldots \ldots$ & $\begin{array}{l}-.005 \\
(-.15)\end{array}$ & $\begin{array}{c}-.01 \\
(-.39)\end{array}$ & $\begin{array}{l}.19^{* *} \\
(2.76)\end{array}$ & $\begin{array}{l}.19^{* *} \\
(2.80)\end{array}$ & $\begin{array}{c}.13 \\
(1.25)\end{array}$ & $\begin{array}{c}.13 \\
(1.25)\end{array}$ \\
\hline White & $\begin{array}{c}-.10^{*} \\
(-2.40)\end{array}$ & $\begin{array}{c}-.09 * \\
(-2.30)\end{array}$ & $\begin{array}{c}.08 \\
(1.06)\end{array}$ & $\begin{array}{c}.08 \\
(.98)\end{array}$ & $\begin{array}{r}-.27 * \\
(-2.29)\end{array}$ & $\begin{array}{r}-.27 * \\
(-2.25)\end{array}$ \\
\hline Age $(10$ years $) \ldots \ldots \ldots$ & $\begin{array}{c}.02 \\
(1.79)\end{array}$ & $\begin{array}{c}.02 \\
(1.69)\end{array}$ & $\begin{array}{l}.001 \\
(.06)\end{array}$ & $\begin{array}{l}.002 \\
(.08)\end{array}$ & $\begin{array}{l}-.19 * * * \\
(-5.57)\end{array}$ & $\begin{array}{l}-.19 * * * \\
(-5.58)\end{array}$ \\
\hline Education (years) ..... & $\begin{array}{l}-.004 \\
(-.65)\end{array}$ & $\begin{array}{c}-.01 \\
(-.82)\end{array}$ & $\begin{array}{l}.03 * \\
(1.98)\end{array}$ & $\begin{array}{c}.03 * \\
(2.02)\end{array}$ & $\begin{array}{l}.01 \\
(.67)\end{array}$ & $\begin{array}{l}.01 \\
(.63)\end{array}$ \\
\hline Log of network size $\ldots$ & $\begin{array}{l}-.02 \\
(-.76)\end{array}$ & $\begin{array}{r}.001 \\
(-.04)\end{array}$ & $\cdots$ & $\cdots$ & $\begin{array}{c}-.13 \\
(-1.91)\end{array}$ & $\begin{array}{c}-.13 \\
(-1.86)\end{array}$ \\
\hline \multicolumn{7}{|l|}{ Mental illness: ${ }^{\mathrm{a}}$} \\
\hline Mild disorder $\ldots . .$. & $\begin{array}{c}.07 \\
(1.38)\end{array}$ & $\begin{array}{c}-.06 \\
(-.63)\end{array}$ & $\begin{array}{c}.10 \\
(.98)\end{array}$ & $\begin{array}{c}.19 \\
(1.61)\end{array}$ & $\begin{array}{l}-.39 * * \\
(-2.46)\end{array}$ & $\begin{array}{c}-.41^{*} \\
(-2.27)\end{array}$ \\
\hline Major depression $\ldots$ & $\begin{array}{l}.17 * * * \\
(3.81)\end{array}$ & $\begin{array}{c}-.07 \\
(-.86)\end{array}$ & $\begin{array}{l}.25^{* *} \\
(2.83)\end{array}$ & $\begin{array}{l}.41 * * * \\
(4.15)\end{array}$ & $\begin{array}{l}-.54 * * * \\
(-3.94)\end{array}$ & $\begin{array}{l}-.63 * * * \\
(-4.08)\end{array}$ \\
\hline Bipolar disorder $\ldots$ & $\begin{array}{l}.19^{*} \\
(2.11)\end{array}$ & $\begin{array}{c}-.18 \\
(-1.10)\end{array}$ & $\begin{array}{c}.28 \\
(1.56)\end{array}$ & $\begin{array}{l}.55 * * \\
(2.71)\end{array}$ & $\begin{array}{l}.01 \\
(.02)\end{array}$ & $\begin{array}{l}.12 \\
(.36)\end{array}$ \\
\hline Schizophrenia ...... & $\begin{array}{c}.10 \\
(1.15)\end{array}$ & $\begin{array}{l}.11 \\
(.60)\end{array}$ & $\begin{array}{c}.16 \\
(1.05)\end{array}$ & $\begin{array}{c}.32 * \\
(1.95)\end{array}$ & $\begin{array}{c}-.31 \\
(-1.28)\end{array}$ & $\begin{array}{c}-.21 \\
(-.80)\end{array}$ \\
\hline Time (years) & $\begin{array}{l}.01 \\
(.57)\end{array}$ & $\begin{array}{c}-.09 * \\
(-2.33)\end{array}$ & $\begin{array}{c}.07 * * \\
(2.80)\end{array}$ & $\begin{array}{l}.19 * * * \\
(4.82)\end{array}$ & $\begin{array}{c}.09 * \\
(2.15)\end{array}$ & $\begin{array}{c}.06 \\
(1.03)\end{array}$ \\
\hline \multicolumn{7}{|l|}{ Interaction terms: } \\
\hline Time $\times$ mild $\ldots \ldots \ldots$ & $\cdots$ & $\begin{array}{c}.10 \\
(1.62)\end{array}$ & . . & $\begin{array}{c}-.11 \\
(-1.52)\end{array}$ & . . & $\begin{array}{c}.02 \\
(.15)\end{array}$ \\
\hline Time $\times$ depression $\ldots$ & . . & $\begin{array}{l}.17 * * * \\
(3.27)\end{array}$ & $\cdots$ & $\begin{array}{l}-.21 * * * \\
(-3.62)\end{array}$ & $\cdots$ & $\begin{array}{c}.13 \\
(1.29)\end{array}$ \\
\hline Time $\times$ bipolar $\ldots .$. & $\cdots$ & $\begin{array}{l}.25^{* *} \\
(2.78)\end{array}$ & $\cdot \cdot$ & $\begin{array}{l}-.34 * * * \\
(-2.97)\end{array}$ & $\cdots$ & $\begin{array}{c}-.13 \\
(-.72)\end{array}$ \\
\hline Time $\times$ schizoph.... & . . & $\begin{array}{l}-.01 \\
(-.09)\end{array}$ & $\cdots$ & $\begin{array}{c}-.26^{*} \\
(-2.06)\end{array}$ & $\cdots$ & $\begin{array}{c}-.41 \\
(-1.22)\end{array}$ \\
\hline Constant $\ldots \ldots \ldots \ldots \ldots$ & .53 & .66 & .42 & .33 & 4.60 & 4.63 \\
\hline Observations $\ldots \ldots \ldots$ & 392 & 392 & 705 & 705 & 647 & 647 \\
\hline Likelihood ratio $\chi^{2} \ldots$ & $28.35 * *$ & $42.85 * * *$ & $28.84 * * *$ & $47.83 * * *$ & $53.30 * * *$ & $57.82 * * *$ \\
\hline
\end{tabular}

Note.-The table presents unstandardized coefficients, variance-constrained models; numbers in parentheses are $Z$-values. Demographics are at baseline.

${ }^{\text {a }}$ The comparison group is the general population (no self-reported mental illness).

$* P<.05$ (two-tailed test).

$* * P<.01$.

$* * * P<.001$ 


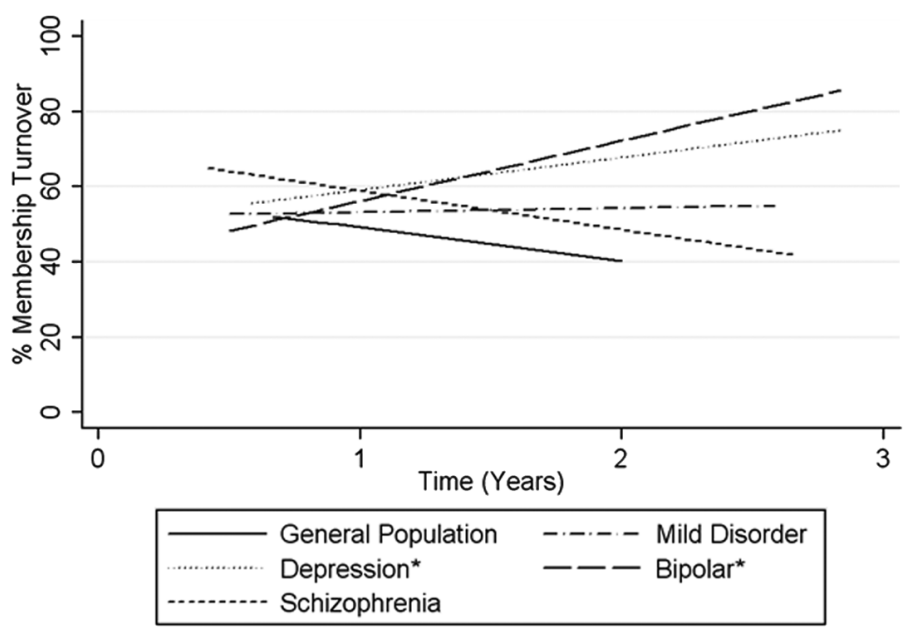

FIG. 2.-Change in predicted percentage of membership turnover in the core health network over time for the general population and people with mental illness, INMHS and INGPS. Predicted values are based on a pooled interactive model, controlling for demographic variables. * indicates that group differences in slope coefficients are significant at $P<.05$. Comparison group is the general population (no self-reported mental illness); twotailed test.

Results from the baseline model indicate that the size of the core health network increases significantly over time when the mental illness and general population samples are combined (model $3 ; b=0.07, P \leq .01$ ). This belies important group differences that emerge when interaction terms are included (table 3, model 4). According to figure 3 , the size of the core health network increases over time from about 2.9 to 4.2 members for individuals who report no current or past psychiatric diagnosis ( $b=0.19, P \leq .001)$. For those labeled with a mild mental illness, the size of the core health network also increases slightly over a three-year period $(b=0.08)$, with no significant difference from those without a mental illness. Conversely, the size of the health network decreases slightly for those with depression $(b=-0.02, P \leq .001)$ and schizophrenia $(b=$ $-0.07, P \leq .05)$ and decreases sharply from about 5.0 to 3.3 members for those with bipolar disorder $(b=-0.15, P \leq .001)$.

Model $\mathrm{V}$ reveals that individuals labeled with a mild mental illness $(b=-0.39, P \leq .01)$ and with depression $(b=-0.54, P \leq .001)$ report less broadly supportive core health networks than those with no labeled psychiatric disorder. However, the support functions provided by health networks increase significantly over time for the sample as a whole ( $b=0.09, P \leq .05)$. According to model 6 , there are no statistically significant differences between groups in this trend. 


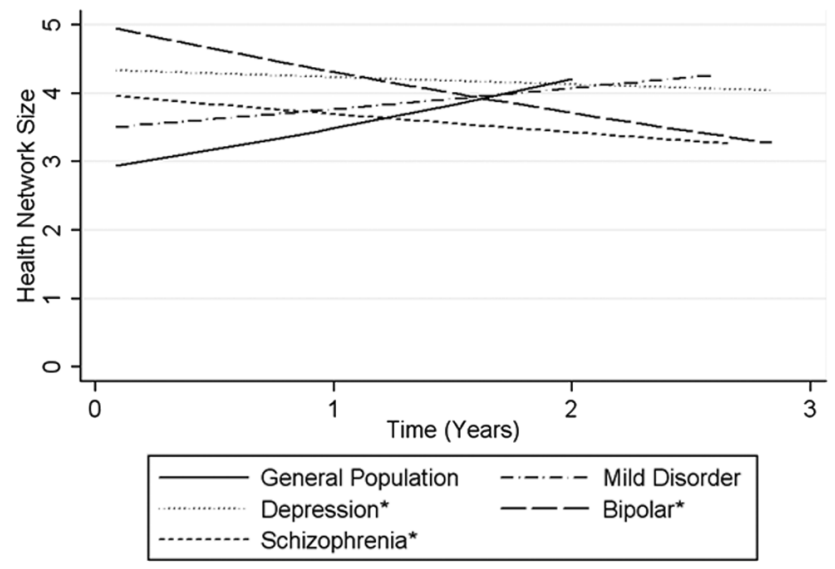

FIG. 3.-Change in predicted size of the core health network over time for the general population and people with mental illness, INMHS and INGPS. Predicted values are based on a pooled interactive model, controlling for demographic variables. * indicates that group differences in slope coefficients are significant at $P<.05$. Comparison group is the general population (no self-reported mental illness); two-tailed test.

Thus, results on core health networks provide only partial support for our hypotheses. Consistent with hypothesis 2 , membership in the health networks of individuals labeled with severe affective disorders becomes increasingly dynamic over time, whereas the health networks of people in the general population and those labeled with mild disorders and schizophrenia become more stable. Also, the core health networks of people labeled with mental illness and the general population are initially quite broadly functional and become increasingly so over time. Finally, consistent with hypothesis $3 \mathrm{~b}$, the health networks of individuals labeled with severe mental illness tend to shrink over time as they progress through the treatment career. However, these networks are significantly larger than those of people without a psychiatric disorder at the point of entry into the mental health treatment system, and predicted values of health network size for those labeled with mental illness never dip below baseline levels reported by the general population.

Total networks.-Data limitations do not permit a comparison of the general population and mental illness samples with respect to total networks. Thus, individuals labeled with mild disorders serve as the comparison group for analyses involving the total network. While the level of membership turnover in the total network is stable over time across groups (see table 4, models 1 and 2), findings indicate that the size of the total network decreases markedly over time for all mental illness groups (model $3 ; b=-0.12, P \leq .001$ ). Again, there is evidence of differences 
TABLE 4

Random-Effects Linear Regression of Sociodemographics, Mental Illness Status, and Time on Characteristics of the Total Network, INMHS

\begin{tabular}{|c|c|c|c|c|c|c|}
\hline & \multicolumn{2}{|c|}{$\begin{array}{l}\% \text { MeMbershiP } \\
\text { TuRnOVER }\end{array}$} & \multicolumn{2}{|c|}{$\begin{array}{c}\text { Log of NeTwORK } \\
\text { SIZE }\end{array}$} & \multicolumn{2}{|c|}{$\begin{array}{l}\text { MEAN Number OF } \\
\text { SuPPORT FUnCTIONS }\end{array}$} \\
\hline & 1 & 2 & 3 & 4 & 5 & 6 \\
\hline Female & $\begin{array}{l}-.01 \\
(-.20)\end{array}$ & $\begin{array}{l}-.01 \\
(-.18)\end{array}$ & $\begin{array}{r}.13^{*} \\
(1.93)\end{array}$ & $\begin{array}{c}.13^{*} \\
(1.94)\end{array}$ & $\begin{array}{c}.20 \\
(1.59)\end{array}$ & $\begin{array}{c}.20 \\
(1.59)\end{array}$ \\
\hline White & $\begin{array}{c}.04 \\
(1.22)\end{array}$ & $\begin{array}{c}.04 \\
(1.21)\end{array}$ & $\begin{array}{l}.05 \\
(.74)\end{array}$ & $\begin{array}{l}.05 \\
(.73)\end{array}$ & $\begin{array}{c}-.19 \\
(-1.40)\end{array}$ & $\begin{array}{c}-.18 \\
(-1.38)\end{array}$ \\
\hline Age $(10$ years $) \ldots \ldots \ldots$ & $\begin{array}{l}-.002 \\
(-.16)\end{array}$ & $\begin{array}{l}-.002 \\
(-.17)\end{array}$ & $\begin{array}{c}.03 \\
(1.04)\end{array}$ & $\begin{array}{c}.03 \\
(1.05)\end{array}$ & $\begin{array}{c}-.06 \\
(-1.05)\end{array}$ & $\begin{array}{c}-.06 \\
(-1.04)\end{array}$ \\
\hline Education (years) ..... & $\begin{array}{c}.01 \\
(1.15)\end{array}$ & $\begin{array}{c}.01 \\
(1.24)\end{array}$ & $\begin{array}{l}.04^{* *} \\
(2.71)\end{array}$ & $\begin{array}{l}.04 * * \\
(2.71)\end{array}$ & $\begin{array}{l}.01 \\
(.32)\end{array}$ & $\begin{array}{l}.01 \\
(.34)\end{array}$ \\
\hline Log of network size $\ldots$ & $\begin{array}{l}-.08 * * \\
(-3.08)\end{array}$ & $\begin{array}{l}-.08 * * * \\
(-3.18)\end{array}$ & $\ldots$ & $\cdots$ & $\begin{array}{l}-.32 * * \\
(-2.65)\end{array}$ & $\begin{array}{l}-.33^{* *} \\
(-2.70)\end{array}$ \\
\hline \multicolumn{7}{|l|}{ Mental illness: ${ }^{\mathrm{a}}$} \\
\hline Major depression $\ldots$ & $\begin{array}{l}.01 \\
(.26)\end{array}$ & $\begin{array}{c}.09 \\
(1.38)\end{array}$ & $\begin{array}{c}.12 \\
(1.72)\end{array}$ & $\begin{array}{c}.12 \\
(1.52)\end{array}$ & $\begin{array}{c}-.08 \\
(-.57)\end{array}$ & $\begin{array}{l}-.05 \\
(-.28)\end{array}$ \\
\hline Bipolar disorder & $\begin{array}{l}.06 \\
(.96)\end{array}$ & $\begin{array}{c}.14 \\
(1.29)\end{array}$ & $\begin{array}{c}.17 \\
(1.32)\end{array}$ & $\begin{array}{c}.33 * \\
(2.23)\end{array}$ & $\begin{array}{c}.48 \\
(1.87)\end{array}$ & $\begin{array}{r}.64 * \\
(2.04)\end{array}$ \\
\hline Schizophrenia ... & $\begin{array}{l}.02 \\
(.37)\end{array}$ & $\begin{array}{l}.06 \\
(.55)\end{array}$ & $\begin{array}{l}.06 \\
(.55)\end{array}$ & $\begin{array}{c}.06 \\
(.54)\end{array}$ & $\begin{array}{l}.06 \\
(.29)\end{array}$ & $\begin{array}{l}.16 \\
(.63)\end{array}$ \\
\hline Time (years) $\ldots \ldots \ldots \ldots$ & $\begin{array}{l}-.004 \\
(-.21)\end{array}$ & $\begin{array}{c}.03 \\
(1.10)\end{array}$ & $\begin{array}{l}-.12 * * * \\
(-5.49)\end{array}$ & $\begin{array}{l}-.11^{* *} \\
(-2.54)\end{array}$ & $\begin{array}{l}.31^{* * * *} \\
(5.23)\end{array}$ & $\begin{array}{l}.37 * * * \\
(3.36)\end{array}$ \\
\hline \multicolumn{7}{|l|}{ Interaction terms: } \\
\hline Time $\times$ depression $\ldots$ & . . & $\begin{array}{c}-.06 \\
(-1.42)\end{array}$ & . & $\begin{array}{c}-.002 \\
(-.03)\end{array}$ & $\cdots$ & $\begin{array}{c}-.04 \\
(-.29)\end{array}$ \\
\hline Time $\times$ bipolar $\ldots .$. & $\cdots$ & $\begin{array}{c}-.06 \\
(-.95)\end{array}$ & $\cdots$ & $\begin{array}{c}-.19^{*} \\
(-2.27)\end{array}$ & $\cdots$ & $\begin{array}{l}-.19 \\
(-.90)\end{array}$ \\
\hline Time $\times$ schizoph.... & $\cdots$ & $\begin{array}{l}-.03 \\
(-.37)\end{array}$ & $\ldots$ & $\begin{array}{c}-.003 \\
(-.02)\end{array}$ & $\cdots$ & $\begin{array}{l}-.17 \\
(-.72)\end{array}$ \\
\hline Constant $\ldots \ldots \ldots \ldots \ldots$ & .61 & .55 & 1.88 & 1.87 & 3.33 & 3.31 \\
\hline Observations $\ldots \ldots \ldots$ & 202 & 202 & 373 & 373 & 353 & 353 \\
\hline Likelihood ratio $\chi^{2} \ldots$ & 13.69 & 15.96 & $43.34 * * *$ & $49.38 * * *$ & $51.54 * * *$ & $52.69 * * *$ \\
\hline
\end{tabular}

Note.-The table presents unstandardized coefficients, variance-constrained models; numbers in parentheses are $Z$-values. Demographics are at baseline.

${ }^{a}$ The comparison group is mild disorder.

$* P<.05$ (two-tailed test).

$* * P<.01$.

$* * * P<.001$.

across mental illness categories (model 4). Figure 4 reveals that people labeled with a mild disorder $(b=-0.11, P \leq .01)$, depression $(b=$ $-0.11)$, and schizophrenia $(b=-0.11)$ report a loss of about four individuals from their total networks over a three-year period, with no significant group differences. Remarkably, individuals labeled with bipolar disorder report losing more than half of their network members, with the total network shrinking from about 20.0 to 8.8 associates over three years $(b=-0.40, P \leq .05)$.

Though there is considerable decay in the size of the total network, it becomes increasingly supportive over time for the entire mental illness 


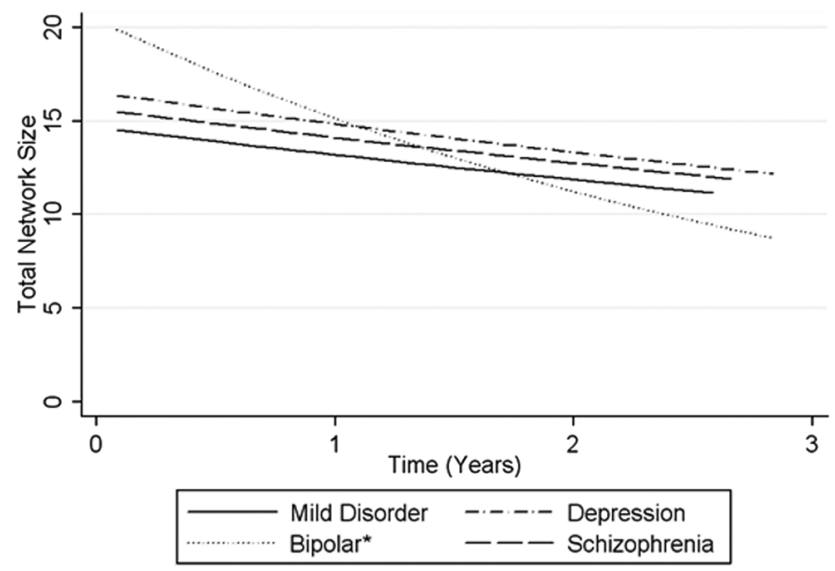

FIG. 4.-Change in predicted size of the total network over time for people with mental illness, INMHS. Predicted values are based on a pooled interactive model, controlling for demographic variables. * indicates that group differences in slope coefficients are significant at $P<.05$. Comparison group is mild disorder; two-tailed test.

group (model $5 ; b=0.31, P \leq .001$ ). To determine whether changes in the functionality of ties may be related to patterns of network attrition, analyses comparing characteristics of associates who remained in the network and those who exited were conducted. Decrease in total network size is largely driven by the exit of less broadly supportive associates from the network rather than increasing functionality among stable network members. The mean number of support functions provided by stable friends and family members (i.e., those present across multiple waves of the study) increases only slightly from 2.8 to 3.0 over a three-year period. Conversely, associates who drop out of the network fulfill only 2.1 different functions compared to an average of 2.8 among those who stay. These findings suggest that weaker ties in the total network dissolve over time, whereas stronger, more functional ties remain intact.

To explore this possibility further, additional analyses were conducted to determine which types of associates are most likely to exit the network. The decay of the network as a whole is attributable, in large part, to a marked decrease in the number of kin $(b=-0.16, P \leq .001$; fig. 5). Though the sizes of the professionals $(b=-0.12, P \leq .01)$ and friend $(b=-0.10, P \leq .01)$ networks also decrease significantly over time, the magnitude of this effect is much larger in the kin network (particularly since these $\beta$ 's reflect logged values). In fact, respondents stop having regular and/or resource-rich contact with an average of 2.7 family members over three years (see fig. 5). As a follow-up on this finding, post hoc 


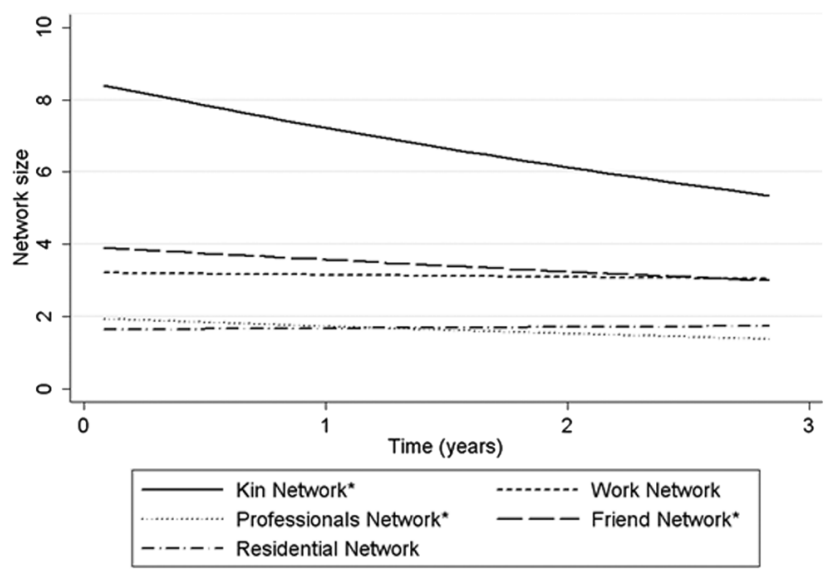

FIG. 5.-Change in predicted size of the kin, work, professionals, friend, and residential networks over time for people with mental illness, INMHS. Predicted values are based on five separately modeled dependent variables. $*$ indicates that slope coefficients for time (years) are significant at $P<.05$ (two-tailed test).

analyses indicate that about $49 \%$ of family members who exit the network are extended kin (aunts/uncles, grandparents, cousins, etc.) and in-laws, compared to only $22 \%$ of those who stay in the network. In contrast, $78 \%$ of kin who remain in the network are close relatives such as spouses or partners, parents, siblings, and children.

Results from analyses examining network attrition among individuals who begin with large and small networks (see fig. 6) provide evidence for hypothesis $3 \mathrm{~b}$. Peripheral supporters temporarily enter the network to help cope with the acute episode, consistent with hypothesis 1 , and then exit the network when the crisis abates. A regression model that includes an interaction term for size of the network at baseline $\times$ time provides evidence for significant group differences. As depicted in figure 6, individuals who start with small to medium total networks (i.e., those who fall in the bottom two-thirds of the distribution on network size) lose about 2.5 members as individuals progress through the treatment career, on average $(b=-0.09, P \leq .001)$. However, those who begin with large networks (i.e., those in the top one-third of the distribution) lose about 11.0 ties over the same period $(b=-0.21, P \leq .01)$. That is, larger and smaller networks tend to converge over time on a number of friends and family members that is similar relative to levels at point of entry into treatment. Moreover, network size is significantly correlated with both functionality $(r=-0.16, P \leq .01)$ and kinship composition $(r=0.68$, 


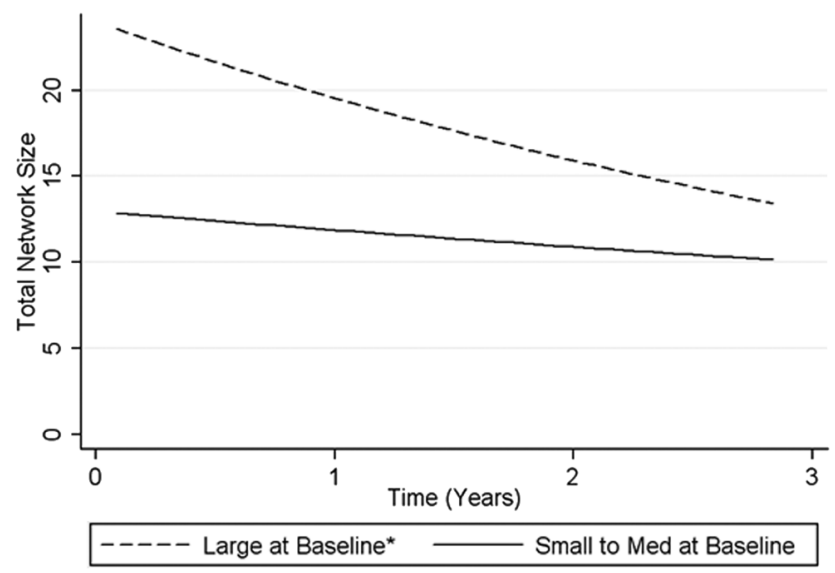

FIG. 6.-Change in predicted size of the total network over time for people with mental illness who began with small to medium and large networks at baseline, INMHS. Predicted values are based on a pooled interactive model, controlling for demographic variables. * indicates that group differences in slope coefficients are significant at $P<.05$. Comparison group is small to medium at baseline; two-tailed test.

$P \leq .001)$ such that larger networks tend to provide fewer different kinds of support functions and contain larger numbers of kin, on average.

In sum, there is evidence of substantial attrition in the total network for individuals with serious mental illness over time, particularly for those with bipolar disorder. However, this network also becomes increasingly functional, providing more different kinds of support. Less broadly functional supporters and extended kin are most likely to exit the network, whereas more helpful ties and relationships with close family members remain intact. Finally, people with very large networks at baseline are more vulnerable to network attrition than those who entered treatment with medium or small networks.

\section{DISCUSSION: NETWORKS AND BIOGRAPHICAL DISRUPTION}

We posed fundamental questions about how biographical disruption (Bury 1982) shapes social network dynamics over the course of three years. Classic sociological work (Davis 1963; Strauss 1975) focused on the interactional repercussions of illness. This theoretical agenda continues in recent work on mental illness (Cardano 2010), cancer (Hubbard, Kidd, and Kearney 2010; Reeve et al. 2010), hepatitis C (Harris 2009), and cystic fibrosis (Williams et al. 2009), following in that narrative tradition (see Green, Todd, and Pevalin [2007] as an exception). In this article, we return 
to Bury's theoretical concerns, taking up his charge to move "from descriptive categories of interaction" to examine the impact of key transitions and turning points in illness careers. We draw from the SOS framework (Pescosolido 1992) and its derivative model tailored to illness, the NEM (Pescosolido 1991, 2006).

Overall, our results support key principles of network theory. Our unique findings on starting points suggest that individuals coping with a disruptive illness episode have networks that are larger and more broadly functional at what is arguably the height of crisis than do those in the general population with no self-reported mental health problems (Carpentier et al. 1999; Muhlbauer 2002; Sharfstein 2009). This pattern is consistent with our first hypothesis on network response to elevated support needs and provides evidence that coping with a disruptive episode calls for increased social contact with others. As expected, friends and family members are available to provide support and advice to help with the initial stages of disruption and its fallout (Lipton et al. 1981; Breier and Strauss 1984). ${ }^{10}$

Following from the basic idea that managing a disruptive episode is a social process, the NEM argues that these experiences affect characteristics of social networks over time, shaping structure, function, and content as people move through different stages of a career. Our longitudinal findings underscore this assertion but provide only partial support for our second hypothesis. Specifically, we find that the networks of people experiencing an illness episode are characterized by higher levels of membership turnover and more pronounced changes in network size over time compared to people not in crisis, though dynamic patterns in functionality do not differ across groups. Likewise, for people with some severe disorders, the rate at which people enter and exit the core health network escalates with progression through the illness career. This level of instability is not markedly different from rates of membership turnover re-

\footnotetext{
${ }^{10}$ An alternative explanation for the influx of supporters early in the treatment career is the increasing participation of health services providers, but we find no support for this (see Perry and Pescosolido 2010). For individuals labeled with mental illness, only $7 \%$ of the core health network is made up of health professionals at baseline, on average, and the median is $0 \%$. That is, about $78 \%$ of people experiencing a mental health crisis do not mention any medical or mental health professionals in response to a name generator asking specifically whom they talk to about health. Surprisingly, respondents in the general population sample actually nominate more professionals to their core health network than those labeled with a disorder (13\%). These figures remain stable across the three waves of the study. Given that the proportion of professionals in the networks is typical and is not simply a function of mental health status or entry into treatment, the patterns of social network dynamics found here cannot be attributed to contact with health service providers.
} 
ported for other disruptions (Morgan et al. 1997; Suitor and Keeton 1997). ${ }^{11}$

With respect to how network size and functionality evolve over time, our findings are compelling, marking the complexity of the social dynamics involved in biographical disruption. Specifically, core health and total networks become simultaneously smaller and more broadly supportive. Individuals who received a formal label of severe mental illness experience declines in the size of the core health network following entry into treatment; however, these individuals begin with larger networks, on average, relative to people not reporting a crisis. In contrast, the level of attrition in the total network containing both core and peripheral ties is large and significant. Network size shrinks by one-quarter (for those with depression) to one-half (for those diagnosed with bipolar disorder) compared to point of entry into treatment.

A closer look at dynamic patterns of functionality of social networks offers a slightly different picture. Both health and total networks provide a large number of emotional and instrumental support functions, and this level of assistance actually increases slightly across a three-year period. Importantly, this pattern is not attributable to existing members of the network doing more but to the exit of less functional friends and family members. As individuals progress through the treatment career, people with mental illness begin to interact less intensely with those who fulfill fewer support functions. Moreover, attrition is driven largely by individuals who have networks that are swollen with what are likely "temporary helpers"-extended kin and others who fulfill a limited number of functions.

When considered in the broader context of career transitions and turning points, our findings are consistent with the NEM. The illness career is characterized by interdependent patterns and pathways of social interactions and experiences. Different stages of disruptive episodes require unique types and amounts of support and elicit distinct patterns of network change. For these individuals with recent-onset mental illness, we see at least three possible mechanisms underlying dynamic patterns observed following entry into treatment.

First, mental health services offer a formal safety net created by medical, mental health, and social service professionals, allowing informal and

\footnotetext{
${ }^{11}$ For instance, in their study of recent widows, Morgan et al. (1997) found that $78 \%$ of ties were dropped from at least one of seven time points over the course of a year. Suitor and Keeton (1997) report that $66 \%$ of support ties named by adults returning to college in midlife did not persist across three waves of data collected over a decade. In addition, relative to the measure of turnover reported here, which considers change associated with the addition of new ties, findings reported in these studies probably underestimate membership instability.
} 
temporary supporters to become less intensely involved in the crisis. However, because only about one-third of people with mental illness who seek formal care remain in treatment longer than a few months (Kessler et al. 2005), this support system is often short-lived. As individuals with mental illness enter and exit treatment programs, this may affect relationships with people both within and outside of the mental health system. This is consistent with Feld's (1981) theory of shared foci of activity, which argues that social networks (and, by extension, their characteristics) are formed and sustained by participation in social contexts, organizations, and activities.

Second, decreases in network size simultaneous to increasing functionality may be attributable to elevated levels of stigma following formal labeling with a mental illness. The loss of status associated with receiving mental health treatment could lead to rejection by more peripheral sectors of the network (Perry 2011). Conversely, labeled individuals may withdraw from social interaction with all but their closest friends and family members to avoid experiencing stigma (Link et al. 1989, 2004). In addition, weaker ties not governed by norms of immediate kinship and a history of shared reciprocity may dissolve if relationships remain unbalanced over long periods of time (Grant and Wenger 1993; Williams 1995). Our finding that severe illness can lead to loss of peripheral ties over time is consistent with the conclusion of other researchers and with the suggestion that this pattern may have adverse consequences for individuals' sense of power and independence, as well as access to novel resources and information (Cornwell 2009).

Third, patterns of network attrition in our data may reflect a return to normal network levels following an influx of supplementary supporters recruited to help manage the initial crisis. Extended family members or friends may be temporarily activated when support needs are greatest but do not provide long-term assistance, particularly after a safety net of formal treatment providers is in place (Carpentier et al. 1999; Karp 2001; Muhlbauer 2002). Eventually, individuals accept or are forced to adjust to their identity as a person with mental illness and to a new rhythm of social life, much as most people eventually adapt to events such as divorce, widowhood, or migration (Terhell et al. 2004; Lubbers, Snijders, and Van Der Werf 2010). As crisis and uncertainty abate following entry into treatment, the need to discuss illness with others subsides (Perry, in press). Health becomes less of an issue, with instability in networks reflecting changes in what people talk about with friends and family rather than real relationship dissolution. In short, social network attrition does not necessarily indicate rejection or stigmatized social processes and may actually signal progress toward recovery and independence. ${ }^{12}$

${ }^{12}$ This dynamic pattern is more pronounced among those with severe mental illness, 
While our analysis focused on individuals recently labeled with a mental illness, we believe that the general pattern identified (i.e., temporary support activation to cope with a period of acute crisis) is applicable to many other illnesses and social phenomena. For example, Parsons (1951) argued early on that individuals who are granted the sick role by their community-based social networks are eligible for increased assistance and a reprieve from normal roles and obligations, consistent with our findings. However, this is a temporary social arrangement designed to facilitate a return to wellness, calling into question whether peripheral supporters are willing to extend help over long periods of time for those with chronic illness (Lipton et al. 1981). Likewise, individuals are more likely to provide supplemental and temporary support when stressors are "unambiguous and visibly distressing-where potential providers recognize the need, see it as legitimate, and know how to help" (Kaniasty and Norris 1993, pp. 395-96; Haines, Hurlbert, and Beggs 1996; Perry 2011). In sum, then, we expect to observe these patterns of social network dynamics in response to acute illness or in the early stages of chronic illness, when prognosis is severe and uncertain, and when a person's needs exceed the resources of the smaller, core network of regular supporters. However, we suspect that the patterns of network change we identified in our sample with serious mental illness may actually be observed on a greater scale among people with severe, acute physical illnesses such as a stroke or treatable cancer. Individuals with physical health problems have reported larger support networks, from both informal and formal sources, than those experiencing emotional problems (Neighbors and Jackson 1984; Chatters, Taylor, and Neighbors 1989). Even more generally, our findings support the now "quite general finding" (Lubbers et al. 2010, p. 102) that stronger ties tend to be more persistent ties.

Yet, our findings reveal new insights into dynamic processes. Unlike past studies, we are able to mark changes in biographical disruption in contrast to and in the context of the "everyday" dynamic of a sample of individuals in the general population that report no such problems, now or in the past. Of course, we realize that the screener of "self-reported" mental health problems may be subject to error. However, what is most

possibly reflecting exaggerated network size at baseline due to initial pathology (i.e., grandiosity, increased sociability) and a return to more accurate levels as symptoms improved. However, using these same data, Pescosolido and Wright (2004) compared accounts of health matters networks provided by respondents with mental illness (focal respondents; FRs) and their network members (network respondents; NRs). They found that reports of network size at baseline provided by NRs were significantly larger than those given by FRs, providing evidence that baseline accounts were probably not exaggerated. In addition, when comparing actual network membership, they found that there was more overlap in FR and NR reports among those with more severe illnesses and larger networks. 
interesting is the pattern of reporting slightly less turnover and a slightly greater increase in social networks over time. Even if this is a learning effect due to familiarity with the topic of the survey or even reflection between waves, what is startling is the fundamental difference in trajectory between INMHS and INGPS respondents. We can reject, for the first time, alternative explanations of measurement effects in single sample studies or simply expected "ups and downs" in social networks for all individuals.

\section{Looking Ahead: Limitations and Future Research}

An important limitation is the absence of information about the personal network structures and trends before the onset of mental illness or before contact with the mental health treatment system. As suggested by the NEM (Pescosolido 1991), negotiations between individuals experiencing "symptoms" and their network ties can influence the nature of treatment contact and whether contact occurs at all. Thus, the individuals who ended up in the mental health system, and therefore in the INMHS sample, may have social networks that differ in some ways from the networks of those who never seek treatment. We do know that the influence of social networks on getting into health services depends not only on their size but on whether the beliefs in those networks encourage the use of formal sources of care (Kadushin 2012) or see health care as a failure of family support systems (Pescosolido et al. 1998). However, contact with the formal treatment system itself may influence how social networks change over time, not only because symptoms can change but "wraparound" services can structure future interaction (Holschuh and Segal 2002; Pescosolido and Boyer 2010). Though the examination of social networks at baseline was intended to address this limitation to the degree possible using these data, additional research is needed to follow individuals across the entire illness career.

Future social network research should adopt a more direct focus on understanding the organization and function of both core networks and peripheral social relationships. On the one hand, our findings suggest that when observing the relationship between network dynamics and progression through event-centered biographical disruptions or life course stages, it is crucial to examine the networks most likely to be accessed as people confront issues and make decisions (Morgan 1989; Suitor and Keeton 1997). On the other hand, had we looked only at patterns of network dynamics in the core networks of people with mental illness, the level of network attrition in the extended network relative to the core would not have come to light. Indeed, the importance of weaker ties represents a classic sociological contribution (Granovetter 1973; Mok and Wellman 
2007). We end by suggesting that understanding network dynamics requires a consideration of structural change in light of the type, content, and meaning of ties in simultaneous networks that make up the individual's social world. The juxtaposition of our findings on specific versus total network dynamics raises the question of what forces (e.g., interest, emotion, role loss) keep ties in the core network and what attracts the extended networks elsewhere or repels them away from the networks in which they once interacted.

\section{Beyond Mental Illness: General Theoretical Implications}

What do our findings on mental illness contribute to a sociological understanding of social network dynamics more generally? First, timing matters. Most biographical disruptions develop and are resolved over an extended period of time and are more aptly characterized as careers or episodes rather than events. Though our data do not capture the entire illness or treatment career, they do provide clues about patterns of social network response at different stages. Most notably, these findings indicate that the social safety net is large, is supportive, and contains many peripheral ties (e.g., extended kin) during the period of intense crisis. However, this level of support and activity declines over time, and the safety net eventually shrinks down to a smaller group of broadly functional friends and immediate family members. These findings provide evidence that patterns of network dynamics are dependent on one's stage in the coping or adjustment process, consistent with the SOS framework, NEM, and notions of network dynamics more generally (e.g., Haines et al. 1996). Because disruptive events are characterized by a set of challenges, support needs, and motivations that evolve and unfold over time, it is critical to examine network activation processes longitudinally (Terhell et al. 2004).

Moreover, people who remain in social networks over longer periods of time tend to be those who fulfill a broad range of support needs. This suggests a need for additional research to determine the extent to which functionality and the goal-directed activation of social network resources drive dynamic interaction processes during crisis. The temporary activation of latent ties (i.e., recruitment of irregular and supplemental helpers) represents a critical coping mechanism for individuals facing unfamiliar challenges and periods of elevated support needs. Existing research indicates that supporters are drawn into a crisis when there is a clear and immediate need for assistance and when outcomes are uncertain (DunkelSchetter and Skokan 1990; Kaniasty and Norris 1993). When help is most critical, individuals who fulfill latent or less tangible social integration functions under normal circumstances are called on to provide more substantial and instrumental forms of support, such as providing temporary 
housing, loaning money, or helping with housework (Shavit, Fischer, and Koresh 1994). Our findings reflect this general support process and also suggest that temporary helpers may return to their latent status in the years following a disruptive episode. Under what conditions are these same individuals willing to provide elevated levels of support during subsequent periods of crisis? We cannot answer this critical question here.

Our data do point to the central role of kin in the process of temporary activation of informal support-a finding not unique to this research or to the case of illness. For example, Hurlbert et al. (2000) found that support networks with higher proportions of kin were more likely to allocate resources during a natural disaster. Likewise, research on network response in wartime indicates that Israelis called overwhelmingly on family members during Gulf War missile attacks and that reliance on kin was substantially more intense during periods of crisis than in their everyday lives (Shavit et al. 1994). Research suggests that on a routine basis, close, immediate kin provide far more support than extended kin (Wellman and Wortley 1989, 1990). However, our findings underscore that extended kin may also be called on to provide temporary services and emotional support during an unexpected, disruptive episode.

In sum, at the most basic level, our findings complement existing evidence demonstrating that disruption in the lives of individuals reverberates through social networks (Milardo 1987; Leik and Chalkey 1997). We add that the magnitude of this impact may manifest largely in the peripheral sectors of networks, whereas the core group of supporters remains relatively intact (Wellman et al. 1997; Lubbers, Snijders, and Van Der Werf 2010). Periods of stability and instability in social networks reflect evolving needs and resources as people in crisis and those around them learn to manage problems and progress through stages of a disruptive episode. Patterns of network change are unique to individuals with biographical disruption and stand in stark contrast to the dynamics of others who live in the same geographical context.

\section{REFERENCES}

Afifi, Abdelmonem, Jenny B. Kotlerman, Susan L. Ettner, and Marie Cowan. 2006. "Methods for Improving Regression Analysis for Skewed Continuous or Counted Responses." Annual Review of Public Health 28:95-111.

Ajrouch, Kristin J., Toni C. Antonucci, and Mary R. Janevic. 2001. "Social Networks among Blacks and Whites: The Interaction between Race and Age." Journals of Gerontology Series B: Psychological Sciences and Social Sciences 56:S112-S118.

Aschaffenburg, Karen, and Ineke Maas. 1997. "Cultural and Educational Careers: The Dynamics of Social Reproduction.” American Sociological Review 62:573-87.

Bearman, Peter S., and James Moody. 2004. "Suicide and Friendships among American Adolescents." American Journal of Public Health 94 (1): 89-96. 


\section{American Journal of Sociology}

Blazer, Dan. 1983. "Impact of Late Life Depression on the Social Network." American Journal of Psychiatry 140:162-66.

Bost, K. K., M. J. Cox, and C. Payne. 2002. "Structural and Supportive Changes in Couples' Family and Friendship Networks across the Transition to Parenthood." Journal of Marriage and Family 64:517-31.

Breier, Alan, and John Strauss. 1984. "The Role of Social Relationships in Recovery from Psychotic Disorders." American Journal of Psychiatry 141:949-55.

Burt, Ronald S. 2002. "Bridge Decay." Social Networks 24:333-63.

Bury, Michael. 1982. "Chronic Illness as Biographical Disruption." Sociology of Health and Illness 4:167-82.

Cardano, Mario. 2010. "Mental Distress: Strategies of Sense-Making." Health 14:253-71.

Carpentier, Normand, and Francine Ducharme. 2003. "Care-Giver Network Transformations: The Need for an Integrated Perspective." Ageing and Society 23:50725.

Carpentier, Normand, Alain Lesage, and Deena White. 1999. "Family Influence on the First Stages of the Trajectory of Patients Diagnosed with Severe Psychiatric Disorders." Family Relations 48:397-403.

Chatters, L. M., R. J. Taylor, and H. W. Neighbors. 1989. "Size of the Informal Network Mobilized in Response to Serious Personal Problems." Journal of Marriage and Family 51:667-76.

Christakis, Nicholas A., and James H. Fowler. 2008. "The Collective Dynamics of Smoking in a Large Social Network." New England Journal of Medicine 358:2249-58.

Coleman, James S. 1982. The Asymmetric Society. Syracuse, N.Y.: Syracuse University Press.

Collins, Linda, and Aline Sayer. 2001. New Methods for the Analysis of Change. Washington, D.C.: American Psychological Association.

Cornwell, Benjamin. 2009. "Good Health and the Bridging of Structural Holes." Social Networks 31:92-103.

Cuijpers, Pim, and Heleen Stam. 2000. "Burnout among Relatives of Psychiatric Patients Attending Psychoeducational Support Groups.” Psychiatric Services 51:375-79.

Cusack, Jason, Frank P. Deane, Coralie J. Wilson, and Joseph Ciarrochi. 2004. "Who Influences Men to Go to Therapy? Reports from Men Attending Psychological Services." International Journal for the Advancement of Counseling 26:271-83.

Davis, Fred. 1963. Passage through Crisis: Polio Victims and Their Families. Indianapolis: Bobbs-Merrill.

Degenne, A., and M.-O. Lebeaux. 2005. "The Dynamics of Personal Networks at the Time of Entry into Adult Life." Social Networks 27:337-58.

Dunkel-Schetter, Christine, and Laurie A. Skokan. 1990. "Determinants of Social Support Provision in Personal Relationships." Journal of Social and Personal Relationships 7:437-50.

Elder, Glenn, and Eliza Pavalko. 1993. "Work Careers in Men's Later Years: Transitions, Trajectories, and Historical Change." Journal of Gerontology 48:S180-S191.

Erikson, Kai T. 1976. Everything in Its Path: Destruction of Community in the Buffalo Creek Flood. New York: Simon \& Schuster.

Feld, Scott L. 1981. "The Focused Organization of Social Ties." American Journal of Sociology 86:1015-35.

Feld, Scott L., J. Jill Suitor, and Jordana Gartner Hoegh. 2007. "Describing Changes in Personal Networks over Time." Field Methods 19:218-36.

Fischer, Claude. 1982. To Dwell among Friends: Personal Networks in Town and City. Chicago: University of Chicago Press.

Gallagher, Sally K., and David Mechanic. 1996. "Living with the Mentally Ill: Effects on the Health and Functioning of Other Household Members." Social Science and Medicine 42:1691-1701.

Gallant, Mary P. 2003. "The Influence of Social Support on Chronic Illness Self- 
Management: A Review and Directions for Research." Health Education and Behavior 30:170-95.

Gameiro, Sofia, Jacky Boivin, Maria C. Canavarro, Mariana Moura-Ramos, and Isabek Soares. 2010. "Social Nesting: Changes in Social Network and Support across the Transition to Parenthood in Couples That Conceived Spontaneously or through Assisted Reproductive Technologies." Journal of Family Psychology 24:175-87.

Goffman, Irving. 1961. Asylums: Essays on the Social Situation of Mental Patients and Other Inmates. Garden City, N.J.: Doubleday.

Gould, William. 2005. "Pooling Data and Performing Chow Tests in Linear Regression." Stata Resources and Support, FAQS, http://www.stata.com/support/faqs/stat /awreg.html.

Granovetter, Mark. 1973. "The Strength of Weak Ties." American Journal of Sociology 78:1360-80.

Grant, Gordon, and Clare Wenger. 1993. "Dynamics of Support Networks: Differences and Similarities between Vulnerable Groups." Irish Journal of Psychology 14:79-98.

Green, Gill, Jennifer Todd, and David Pevalin. 2007. "Biographical Disruption Associated with Multiple Sclerosis: Using Propensity Scoring to Assess the Impact." Social Science and Medicine 65:524-35.

Groot, Wim, and Maartje Verberne. 1997. "Aging, Job Mobility, and Compensation.” Oxford Economic Papers 49:380-403.

Haines, Valerie A., Jeanne S. Hurlbert, and John J. Beggs. 1996. "Exploring Determinants of Support Provision: Provider Characteristics, Personal Networks, Community Contexts, and Support Following Life Events." Journal of Health and Social Behavior 37:252-64.

Hammer, Muriel. 1983. "Core and Extended Social Networks in Relation to Health and Illness." Social Science and Medicine 17:405-11.

Harris, Magdalena. 2009. "Troubling Biographical Disruption: Narratives of Unconcern about Hepatitis C Diagnosis." Sociology of Health and Illness 31:1028-42.

Hollingshead, August B., and Frederick C. Redlich. 1958. Social Class and Mental Illness: A Community Study. New York: Wiley.

Holschuh, Jane, and Steven P. Segal. 2002. "Factors Related to Multiplexity in Support Networks of Persons with Severe Mental Illness." Pp. 293-322 in Social Networks and Health, edited by Judith A. Levy and B. A. Pescosolido. New York: JAI/Elsevier Science.

Horwitz, Allan V. 2002. "Culture, Harmful Dysfunction, and the Sociology of Mental Illness." Pp. 267-73 in Culture in Mind: Toward a Sociology of Culture and Cognition, edited by Karen Cerulo. New York: Routledge.

Hubbard, Gill, Lisa Kidd, and Nora Kearney. 2010. "Disrupted Lives and Threats to Identity: The Experiences of People with Colorectal Cancer within the First Year Following Diagnosis." Health 14:131-46.

Hurlbert, Jeanne S., Valerie A. Haines, and John J. Beggs. 2000. "Core Networks and Tie Activation: What Kinds of Routine Networks Allocate Resources in Nonroutine Situations?" American Sociological Review 65:598-618.

Jackson, Paul R. 1988. "Personal Networks, Support Mobilization, and Unemployment." Psychological Medicine 18:397-404.

Kadushin, Charles. 2012. Understanding Social Networks: Concepts, Theories, and Findings. Oxford: Oxford University Press.

Kalmijn, Matthijs. 2003. "Shared Friendship Networks and the Life Course: An Analysis of Survey Data on Married and Cohabitating Couples." Social Networks 25: 231-49.

Kalmijn, Matthijs, and Marjolein Broese van Groenou. 2005. "Differential Effects of Divorce on Social Integration." Journal of Social and Personal Relationships 22: 455-76.

Kaniasty, Krzysztof, and Fran H. Norris. 1993. "A Test of the Social Support Dete- 
rioration Model in the Context of Natural Disaster." Journal of Personality and Social Psychology 64:395-408.

. 1995. "In Search of Altruistic Community: Patterns of Social Support Mobilization following Hurricane Hugo." Community Psychology 23:447-77.

Karp, David. 2001. The Burden of Sympathy: How Families Cope with Mental Illness. New York: Oxford University Press.

Karp, David A., and Valaya Tanarugsachock. 2000. "Mental Illness, Caregiving, and Emotion Management." Qualitative Health Research 10:6-25.

Kessler, Ronald C., Olga Demler, Richard G. Frank, Mark Olfson, Harold Alan Pincus, Ellen E. Walters, Philip Wang, Kenneth B. Wells, and Alan M. Zaslavsky. 2005. "Prevalence and Treatment of Mental Disorders, 1990 to 2003." New England Journal of Medicine 352:2515-23.

Kessler, Ronald C., Cindy L. Foster, William B. Saunders, and Paul E. Stang. 1995. "Social Consequences of Psychiatric Disorders, I: Educational Attainment." American Journal of Psychiatry 152:1026-32.

Kossinets, Gueorgi, and Duncan J. Watts. 2006. "Empirical Analysis of an Evolving Social Network." Science 311:88-90.

Lazer, David, et al. 2009. "Life in the Network: The Coming Age of Computational Social Science." Science 323 (5915): 721-23.

Leik, Robert K., and Mary Anne Chalkey. 1997. "On the Stability of Network Relations under Stress." Social Networks 19:63-74.

Link, Bruce G., Francis T. Cullen, Elmer Struening, Patrick E. Shrout, and Bruce P. Dohrenwend. 1989. "A Modified Labeling Theory Approach to Mental Disorders: An Empirical Assessment.” American Sociological Review 54:400-423.

Link, Bruce G., and Jo C. Phelan. 1999. "The Labeling Theory of Mental Disorder (II): The Consequences of Labeling." Pp. 361-76 in A Handbook for the Study of Mental Health, edited by Allan V. Horwitz and Theresa L. Scheid. Cambridge: Cambridge University Press.

Link, Bruce G., Lawrence H. Yang, Jo C. Phelan, and Pamela Y. Collins. 2004. "Measuring Mental Illness Stigma." Schizophrenia Bulletin 30:511-41.

Lipton, F. R., C. I. Cohen, E. Fischer, and S. E. Katz. 1981. "Schizophrenia: A Network Crisis." Schizophrenia Bulletin 7:144-51.

Litwak, Eugene. 1985. Helping the Elderly: The Complementary Roles of Informal Networks and Formal Systems. New York: Guilford.

Lively, Kathryn J., and Carrie L. Smith. 2010. "Identity and Illness." Pp. 505-26 in The Handbook of the Sociology of Health, Illness, and Healing, edited by B. A. Pescosolido, J. D. McLeod, J. K. Martin, and A. Rogers. New York: Springer.

Loukissa, Dimitra. 1995. "Family Burden in Chronic Mental Illness: A Review of Research Studies." Journal of Advanced Nursing 21:248-55.

Lubbers, Miranda J., José Luis Molina, Jürgen Lerner, Ulrik Brandes, Javier Avila, and Christopher McCarty. 2010. "Longitudinal Analysis of Personal Networks. The Case of Argentinean Migrants in Spain." Social Networks 32:91-104.

Lubbers, Miranda J., Tom A. B. Snijders, and Margaretha P. C. Van Der Werf. 2010. "Dynamics of Peer Relationships across the First Two Years of Junior High as a Function of Gender and Changes in Classroom Composition." Journal of Research on Adolescence 21 (2): 488-504.

Manning, Willard G., and John Mullahy. 2001. "Estimating Log Models: To Transform or Not to Transform?" Journal of Health Economics 20:461-94.

Marsden, Peter V. 1987. "Core Discussion Networks of Americans." American Sociological Review 53:122-31.

Martin, Jack K., Bernice Pescosolido, and Steven A. Tuch. 2000. "Of Fear and Loathing: The Role of 'Disturbing Behavior,' Labels, and Causal Attributions in Shaping Public Attitudes toward People with Mental Illness." Journal of Health and Social Behavior 41:208-23. 
McLeod, Jane D., and Karen Kaiser. 2004. "Childhood Emotional and Behavioral Problems and Educational Attainment." American Sociological Review 69:636-58.

Metzel, Jonathan M. 2003. Prozac on the Couch: Prescribing Gender in the Era of Wonder Drugs. Durham, N.C.: Duke University Press.

Milardo, Robert M. 1987. "Changes in Social Networks of Men and Women Following Divorce." Journal of Family Issues 8:78-96.

Mok, D., and B. Wellman. 2007. "Did Distance Matter before the Internet? Interpersonal Contact and Support in the 1970s." Social Networks 29:430-61.

Morgan, David L. 1989. "Adjusting to Widowhood: Do Social Networks Really Make It Easier?" Gerontologist 29:101-7.

Morgan, David L., and S. J. March. 1992. "The Impact of Life Events on Networks of Personal Relationships: A Comparison of Widowhood and Caring for a Spouse with Alzheimer's Disease." Journal of Social and Personal Relationships 9:563-84.

Morgan, David L., Margaret B. Neal, and Paula Carder. 1997. "The Stability of Core and Peripheral Networks over Time." Social Networks 19:9-25.

Muhlbauer, Susan A. 2002. "Navigating the Storm of Mental Illness: Phases in the Family's Journey." Qualitative Health Research 12:1076-92.

Neighbors, H. W., and J. S. Jackson. 1984. "The Use of Informal and Formal Help: Four Patterns of Illness Behavior in the Black Community." American Journal of Community Psychology 12:629-44.

Parsons, Talcott. 1951. The Social System. New York: Free Press.

Pattison, E. M., D. Defrancisco, P. Wood, H. Frazier, and J. A. Crowder. 1975. "A Psychosocial Kinship Model for Psychotherapy." American Journal of Psychiatry 132:1246-51.

Pavalko, Eliza K., and Shari Woodbury. 2000. "Social Roles as Process: Caregiving Careers and Women's Health." Journal of Health and Social Behavior 41:91-105.

Peek, Kristen M., and Gregory S. O’Neill. 2001. "Networks in Later Life: An Examination of Race Differences in Social Support Networks." International Journal of Aging and Human Development 52:207-29.

Perlick, Deborah A., Jill M. Hohenstein, John F. Clarkin, Richard Kaczynski, and Robert A. Rosenheck. 2005. "Use of Mental Health and Primary Care Services by Caregivers of Patients with Bipolar Disorder: A Preliminary Study." Bipolar Disorder 7:126-35.

Perry, Brea L. 2006. "Understanding Social Network Disruption: The Case of Youth in Foster Care." Social Problems 53:371-91.

- 2011. "The Labeling Paradox: Stigma, the Sick Role, and Social Networks in Mental Illness." Journal of Health and Social Behavior 52:460-77.

- In press. "Coming Untied? Narrative Accounts of Social Network Dynamics from First-Time Mental Health Clients." Sociology of Health and Illness.

Perry, Brea L., and Bernice A. Pescosolido. 2010. "Functional Specificity in Discussion Networks: Social Regulation and the Influence of Problem-Specific Networks on Health Outcomes." Social Networks 32:345-57.

Pescosolido, Bernice A. 1991. "Illness Careers and Network Ties: A Conceptual Model of Utilization and Compliance." Advances in Medical Sociology 2:161-84.

- 1992. "Beyond Rational Choice: The Social Dynamics of How People Seek Help." American Journal of Sociology 97:1096-1134.

. 2006. "Of Pride and Prejudice: The Role of Sociology and Social Networks in Integrating the Health Sciences." Journal of Health and Social Behavior 47:189208.

Pescosolido, Bernice A., and Carol A. Boyer. 2010. "Understanding the Context and Dynamic Social Processes of Mental Health Treatment." Pp. 420-38 in A Handbook for the Study of Mental Health: Social Contexts, Theories, and Systems, edited by Allan V. Horwitz and Teresa L. Scheid. New York: Cambridge University Press.

Pescosolido, Bernice A., Carole Brooks-Gardner, and Kerri Lubell. 1998. "How People 


\section{American Journal of Sociology}

Get into Mental Health Services: Stories of Choice, Coercion and "Muddling Through' from First-Timers." Social Science and Medicine 46:275-86.

Pescosolido, Bernice, and Eric R. Wright. 2004. "A View from Two Worlds: The Convergence of Social Network Reports between Mental Health Clients and Their Ties." Social Science and Medicine 58:1795-1806.

Pescosolido, Bernice A., Eric R. Wright, Margarita Alegria, and Mildred Vera. 1998. "Social Networks and Patterns of Use among the Poor with Mental Health Problems in Puerto Rico." Medical Care 36:1057-72.

Phelan, Jo C., Bruce G. Link, Ann Steuve, and Bernice Pescosolido. 2000. "Public Conceptions of Mental Illness in 1950 and 1996: What Is Mental Illness and Is It to Be Feared?" Journal of Health and Social Behavior 41:188-207.

Rabe-Hesketh, S., and A. Skrondal. 2008. Multilevel and Longitudinal Modeling Using Stata, 2d ed. College Station, Tex.: Stata Press.

Rands, M. 1988. "Changes in Social Networks Following Marital Separation and Divorce." Pp. 13-47 in Families and Social Networks, edited by R. M. Milardo. Newbury Park, Calif.: Sage.

Reeve, Joanne, Mari Lloyd-Williams, Sheila Payne, and Christopher Dowrick. 2010. "Revisiting Biographical Disruption: Exploring Individual Embodied Illness Experience in People with Terminal Cancer." Health 14:178-95.

Roth, Jeffrey A. 1963. Timetables: Structuring the Passage of Time in Hospital Treatment and Other Careers. Indianapolis: Bobbs-Merrill.

Sharfstein, Steven S. 2009. "Goals of Inpatient Treatment for Psychiatric Disorders." Annual Review of Medicine 60:393-403.

Shavit, Yossi, Claude S. Fischer, and Yael Koresh. 1994. "Kin and Nonkin under Collective Threat: Israeli Networks during the Gulf War." Social Forces 72:1197-1215.

South, Scott J., and Glenn D. Deane. 1993. "Race and Residential Mobility: Individual Determinants and Structural Constraints." Social Forces 72:147-67.

Spitzer, Robert L., Janet Williams, Miriam Gibbon, and Michael B. First. 1990. Structured Clinical Interview for DSM-III-R-Patient Edition (SCID-P, Version 1.0). Washington, D.C.: American Psychiatric Press.

StataCorp. 2011. Stata Statistical Software: Release 11. College Station, Tex.: Stata Corp.

Strauss, Anselm L. 1975. Chronic Illness and the Quality of Life. St. Louis: Mosby.

Suchman, Edward A. 1965. "Stages of Illness and Medical Care." Journal of Health and Human Behavior 6:114-28.

Suitor, J. Jill, and Shirley Keeton. 1997. "Once a Friend, Always a Friend? Effects of Homophily on Women's Support Networks across a Decade." Social Networks 19: $51-62$.

Tedeschi, R. G., and L. G. Calhoun. 1996. "The Posttraumatic Growth Inventory: Measuring the Positive Legacy of Trauma." Journal of Traumatic Stress 9:455-71.

Terhell, Elisabeth L., Marjolein I. Broese van Groenou, and Theo van Tilburg. 2004. "Network Dynamics in the Long-Term Period after Divorce." Journal of Social and Personal Relationships 21:719-38.

Thoits, Peggy. 2011. "Perceived Social Support and the Voluntary, Mixed, or Pressured Use of Mental Health Services." Society and Mental Health 1:4-19.

Tilly, Charles. 2001. "Mechanisms in Political Process." Annual Review of Political Science 4:21-41.

U.S. Bureau of Labor Statistics. 2010. "Economic News Release: Employment Situation Summary." U.S. Department of Labor, Washington, D.C.

U.S. Bureau of the Census. 2002. Statistical Abstract of the United States. Washington, D.C.: Government Printing Office.

Van Duijn, M. A. J., J. T. Van Busschbach, and T. A. B. Snijders. 1999. "Multilevel Analysis of Personal Networks as Dependent Variables." Social Networks 21:187209. 
Wellman, Barry, and Kenneth Frank. 2001. "Network Capital in a Multi-level World: Getting Support from Personal Communities.” Pp. 233-73 in Social Capital: Theory and Research, edited by Nan Lin, Karen Cook, and Ronald Bury. Chicago: Gruyter.

Wellman, Barry, and Milena Gulia. 1999. "The Network Basis of Social Support: A Network Is More Than the Sum of Its Ties." Pp. 83-118 in Networks in the Global Village, edited by Barry Wellman. Boulder, Colo.: Westview.

Wellman, Barry, and Scott Wortley. 1989. "Brothers' Keepers: Situating Kinship Relations in Broader Networks of Social Support." Sociological Perspectives 32:273306.

1990. "Different Strokes from Different Folks: Community Ties and Social Support." American Journal of Sociology 96:558-88.

Wellman, Barry, Renita Yuk-lin Wong, David Tindall, and Nancy Nazer. 1997. "A Decade of Network Change: Turnover, Persistence, and Stability in Personal Communities." Social Networks 19:27-50.

Wellman, Beverly. 2000. "Partners in Illness: Who Helps When You Are Sick?" Pp. 143-62 in Complementary and Alternative Medicine: Challenge and Change, edited by Merrijoy Kelner, Beverly Wellman, Bernice Pescosolido, and Mike Saks. Amsterdam: Harwood Academic.

Williams, Brian, Joanne Corlett, Jon. S. Dowell, Joanne Coyle, and Somnath Mukhopadhyay. 2009. "'I've Never Not Had It So I Don't Really Know What It's Like Not To': Nondifference and Biographical Disruption among Children and Young People with Cystic Fibrosis." Qualitative Health Research 19:1443-55.

Williams, Holly A. 1995. "There Are No Free Gifts! Social Support and the Need for Reciprocity." Human Organization 54:401-9.

Wright, Eric R., and Bernice A. Pescosolido. 2002. "Sorry I Forgot: The Role of Recall Error in Longitudinal Personal Network Studies." Pp. 113-29 in Advances in Medical Sociology: Social Networks and Health, vol. 8. Edited by Judith A. Levy and Bernice A. Pescosolido. Greenwich, Conn.: JAI. 